Federal Reserve Bank of Minneapolis

Research Department Staff Report 333

March 2004

\title{
A Unified Theory of the Evolution of International Income Levels
}

\author{
Stephen L. Parente* \\ University of Illinois at Urbana-Champaign \\ Edward C. Prescott* \\ Arizona State University \\ and Federal Reserve Bank of Minneapolis
}

\begin{abstract}
This essay develops a theory of the evolution of international income levels. In particular, it augments the Hansen-Prescott theory of economic development with the Parente-Prescott theory of relative efficiencies and shows that the unified theory accounts for the evolution of international income levels over the last millennium. The essence of this unified theory is that a country starts to experience sustained increases in its living standard when production efficiency reaches a critical point. Countries reach this critical level of efficiency at different dates not because they have access to different stocks of knowledge, but rather because they differ in the amount of society-imposed constraints on the technology choices of their citizenry.
\end{abstract}

*Prescott thanks the National Science Foundation and the University of Minnesota Foundation for research support. The views expressed herein are those of the authors and not necessarily those of the Federal Reserve Bank of Minneapolis or the Federal Reserve System. 


\section{Introduction}

Over the last decade, a fairly complete picture of the evolution of international income levels has emerged. Figure 1 plots the path of income per capita relative to the leader for four major regions of the world going back to 1700 using data from Maddison (1995). In 1700, the living standard of the richest country was less than three times the living standard of the poorest country. ${ }^{1}$ This is the nature of the disparity prior to 1700 as well, as no single country experienced sustained increases in its living standard over the pre-1700 period. After 1700, huge differences in international incomes emerged, as some countries experienced large and sustained increases in their living standards well before others.

England was the first country to develop, that is, to realize sustained increases in per capita income. The exact date at which England began to develop is subject to debate. Some historians, such as Bairoch (1993), place this date at around 1700. Western European countries and countries that were ethnic offshoots of England began to develop shortly thereafter. At first, the increases in income experienced by these early developers were irregular and modest in size. For example, Bairoch (1993) reports that it took England nearly 100 years to double its income from its 1750 level. However, after the start of the twentieth century, these increases have been larger and relatively regular with income doubling every 35 years in these countries-a phenomenon Kuznets (1966) labels modern economic growth.

Countries located in other regions of the world started the development process later. For these countries, the gap in income with the leader continued to widen prior to the time they started modern economic growth. For Latin America, the beginning of the twentieth century is the approximate start of modern economic growth. For Asia, the middle of the twentieth century

\footnotetext{
${ }^{1}$ Bairoch (1993) estimates this difference in 1700 to be smaller than a factor of two.
} 
is the approximate start of modern economic growth. For Africa, modern economic growth has yet to start: although per capita income has increased in the majority of African countries since 1960, the increases have been modest and irregular in the period that has followed. As a result, Africa has continued to lose ground relative to the leader in the 1960-2000 period. Because of these later starting dates, the disparity in international income levels increased to their current levels.

Some countries and regions have dramatically reduced their income gap with the leader subsequent to starting modern economic growth. For example, in the post-World War II period, Western Europe has managed to eliminate much of its income gap with the United States, the leader since 1890. Asia is another region that has been catching up with the leader in this period. The catch-up in Asia, in fact, has been dramatic because of the growth miracle countries of Japan, South Korea, and Taiwan that doubled their income in a decade or less. Latin America, in contrast, is an example of a region that has not eliminated its gap with the leader since starting modern economic growth. Latin American per capita income has remained at roughly 25 percent of the leader for the last 100 years.

A theory of the evolution of international income levels must account for these facts. The theory must generate an initial period with living standards at the pre-1700 level followed by a long transition period to modern economic growth. The theory must generate different starting dates for the transition to modern economic growth across countries. Namely, it must identify some factor or set of factors that differ across countries and that delay the start of the transition by as much as two centuries. The theory must also account for the sizable and persistent differences in living standards that characterize the experience of countries that have been experiencing modern economic growth for as long as 100 years. Finally, the theory must be 
consistent with growth miracles, namely, the large increases in relative income experienced by some initially poor countries in a relatively short period after 1950.

There are well-tested theories of some of these phenomena, but not a comprehensive theory that accounts for all of them. This essay unifies these well-tested theories and examines whether the unified theory can account for all of these phenomena. ${ }^{2}$ A well-tested theory of the first phenomenon, namely, the pattern of an initial period of stagnant living standards followed by a transition to modern economic growth, is provided by Hansen and Prescott (2002). The Hansen and Prescott theory is a combination of two long-standing and successful theories: the classical theory of the pre-1700 period and the neoclassical theory of the post-1900 period.

The classical economists, in particular, Malthus (1797) and Ricardo (1817), developed a theory that accounts well for the constant living standard that characterized the pre-1700 era. The main feature of this theory is an aggregate production function characterized by fixed factors, the most important of which is land. With this traditional production function, increases in knowledge lead to increases in output that are completely offset by increases in population. As a result, living standards do not increase. Economists have also had for a long time a good theory of modern economic growth that has characterized the United States and much of Western Europe since 1900. Solow (1970) developed his growth model specifically to account for this post-1900 pattern of growth. The main feature of this theory is also an aggregate production function, but one with no fixed factor of production. With this modern production function, improvements in technology that lead to more output being produced with the same resources are not offset by increases in population. As a result, living standards rise.

\footnotetext{
${ }^{2}$ Ngai (forthcoming) provides a unification of these theories along the lines of this essay.
} 
Hansen and Prescott (2002) unify the classical and modern growth theories by allowing people to use both the traditional production function and the modern production function. They show that when total factor productivity (TFP) associated with the modern production function reaches a critical level, the economy moves resources out of the traditional sector and into the modern sector. This is the date at which the transition begins. The transition is found to last a long period, roughly a century. The model thus gives rise to a pattern of economic development characterized by a long initial period of economic stagnation, followed by a long transition, followed by modern economic growth, as observed in Western Europe and countries settled by Western Europeans.

The Hansen and Prescott theory is not a theory of the evolution of international income levels because it does not address the issues of different starting dates of the transition to modern economic growth, sizeable income differences for countries experiencing modern economic growth, and growth miracles. Some factor that differs across countries must be added to the Hansen and Prescott theory to make it a theory of the evolution of international income levels.

Parente and Prescott (2000) develop a theory that accounts for the sizable differences in living standards for countries experiencing modern economic growth and that accounts for growth miracles. More specifically, they develop a theory of a country-specific TFP and then introduce this factor into a model in which only the modern production function is available. Their theory of country-specific TFP, which they refer to as a theory of relative efficiency, is based on policy differences. More specifically, the theory shows how various policies that constrain choices of technology and work practices at the level of the production unit determine the aggregate efficiency at which a country uses its resources in production. The development of a theory of relative efficiencies is essential. Despite the fact that there is ample empirical 
evidence that countries differ in relative efficiencies, a theory of international income levels that takes countries' TFPs as exogenous is sterile, because it offers no policy guidance.

In this essay, we augment the Hansen and Prescott theory of economic development with the Parente and Prescott (2000) theory of relative efficiencies and show that the resulting unified theory is a theory of the evolution of international income levels. In this unified theory, a country begins its transition to modern economic growth when the efficiency with which it uses resources in the production of goods and services in the modern sector reaches a critical point. Countries reach this critical level of efficiency at different dates not because they have access to different stocks of knowledge, but rather because they differ in the amount of society-imposed constraints on the technology choices of their citizenry. After a country reaches this critical point it begins to grow, and its income gap with the leader eventually stops increasing. This gap only decreases if there is a subsequent increase in the efficiency at which the late starter uses resources in the modern production function. A large increase in a late starter's relative efficiency is the result of improvements in its policies and institutions.

We show that plausible differences in efficiencies delay the start of the transition to modern economic growth by more than two centuries, as observed in the data. We also show that sizable differences in living standards persist between countries that have been experiencing modern economic growth for as long as 100 years. Lastly, we show that a large increase in a late starter's relative efficiency can give rise to a growth miracle, as observed in Japan, South Korea, and Taiwan. Thus, the unified theory accounts for the way international income levels have evolved.

The essay is organized as follows. Section 2 starts with a review of the classical theory of the pre-1700 income level followed by a review of the neoclassical growth theory of modern 
economic growth. It then concludes with a review of how Hansen and Prescott (2002) combine these two theories into a single theory of economic development. Section 3 deals with the second component of the theory, namely, differences in efficiencies. It reviews the Parente and Prescott (2000) theory of relative efficiencies. Section 4 develops the unified theory of international income levels. In Section 4, a model based on the unified theory is developed and calibrated to the U.K. and U.S. development experiences over the last three centuries. The calibrated model is used to examine the effect of differences in efficiencies across countries on the start of the transition to modern economic growth and the effect of an increase in a country's efficiency on the subsequent path of its per capita GDP. Section 5 examines the development experiences of individual countries and groups of countries over the last three centuries within the context of the theory. Section 6 concludes the essay.

\section{A Theory of Economic Development}

In this section, we present the theory of economic development put forth by Hansen and Prescott (2002). We do this in three stages. First, we describe the classical component of that theory and derive its equilibrium properties. Next, we describe the modern growth component of that theory, and also derive its equilibrium properties. The last stage merges these two components and, in doing so, presents the Hansen and Prescott model of economic development.

Figure 2 describes the general pattern of economic development. More specifically, Figure 2 reports per capita income of the leader country dating back to 2000 B.C. Up until 1700, the living standard in the leader country, or any other country for that matter, displayed no secular increase. These living standards were significantly above the subsistence level. In 1688, for example, the poorest quarter of the population in England-the paupers and the cottagers- 
survived on a consumption level that was roughly one-fourth the national average. ${ }^{3} \mathrm{~A}$ few societies, such as the Roman Empire in the first century, the Arab Caliphates in the tenth century, China in the eleventh century, and India in the seventeenth century, realized some increases in their per capita income. However, these increases were not sustained. After 1700 per capita income in England started to increase. Over the next 150 years, these increases in the leader country were modest and irregular. However, since 1900, these increases have been larger and fairly regular, with per capita income doubling roughly every 35 years.

Technology was not stagnant over any part of this time period. Economic historians have documented a steady flow of technological innovations in this 2000 B.C. to A.D. 1700 period. ${ }^{4}$ Yet these innovations prior to 1700 did not translate into increased living standards. Instead they translated into increased population: as total output increased, the population adjusted so as to maintain a constant level of per capita output. After 1700, these innovations did translate into increases in living standards.

\section{A. Classical Theory: The Pre-1700 Era}

Classical economists, most notably Malthus and Ricardo, devised a theory that accounts well for the constant level of per capita income that characterized the pre-1700 era. The theory predicts a trade-off between living standards and population size. This trade-off exists because population growth is an increasing function of per capita consumption and because there is an important fixed factor of production, namely, land. A key implication of this theory is that there is a constant standard of living to which the economy adjusts. The theory predicts that increases

\footnotetext{
${ }^{3}$ See Maddison (1991, p. 10) and Bairoch (1993, pp. 101-108).

${ }^{4}$ See Mokyr (1990) for a review of this literature.
} 
in the stock of usable knowledge, which could translate into increases in living standards, instead translate into increases in population.

Malthus' theory of population is a biological one rather than an economic one. According to his theory, fertility rises and mortality falls as consumption increases. Being classical, the model has no utility theory and so agents have no decision over the number of children they have. Recently a number of authors, including Tamura (1988), Becker, Murphy, and Tamura (1990), Doepke (2000), Galor and Weil (2000), and Lucas (2002), have generated Malthus-like population dynamics in a neoclassical model with household utility defined over consumption of goods and number of children. These models follow Becker (1960) by having a trade-off between quality and quantity of children.

We do not take their approach in this essay. Instead the approach we take has society through its institutions and policies implicitly determine its population size. Although we similarly add household preferences to the classical theory of production, we do not define household preferences to be over the quantity of household children. Consequently, in this societal theory of population growth, the quantity of children is treated as exogenous from the standpoint of the household.

The reason we take this societal approach to population growth is twofold. First, there is no tested theory of population dynamics, and once modern economic growth begins, demographics play a secondary role in development. Second, and more important, the approach reflects the view that groups of individuals, namely, societies, have had a much larger say in deciding how many children a family has than the family itself. Societies have instituted and continue to institute policies that give them their desired population size. Often the policies of society are not what individual families want. In modern China, for example, a law effectively 
limits many households to one child. By contrast, Iran in the 1980s wanted a higher population and so implemented subsidies to encourage people to have more children. After achieving its objective, the government stopped these subsidies in the 1990s and began to subsidize contraceptives. India today, wanting a lower population growth rate, has set up family planning programs in many regions. In all these cases, the effects of policy upon demographics are dramatic. Even in poor and rural Indian villages, which did not experience any increase in human capital or income, policy has led to a dramatic decline in population growth rates in the late twentieth century.

Why did society choose population size prior to 1700 so as to maintain a constant living standard? The answer relates to the fact that land was an essential input to the production process in the pre-1700 era. In particular, as a valuable resource, land was subject to expropriation by outsiders. Prior to 1700, a small group of people with large amounts of quality-adjusted land and therefore a high living standard could not defend this land from outside expropriators. For this reason, there was a maximal sustainable living standard. Society set up social institutions that controlled population so as to maintain the highest possible living standard consistent with the ability to defend itself from outside expropriators. Once an economy switches to the modern production technology, land is no longer an important input, so its defense is not an issue. At the stage when the modern production technology dominates, society sets up its social institutions that it sees as maximizing living standards subject to a constraint that a society perpetuates itself.

For the purpose at hand, it is not essential that we model society's choices of institutions that affect fertility choices. Instead, it is sufficient to treat the growth rate of population in a simple mechanical way, namely, as a function of average consumption. In order to reflect society's choices, the function must display two properties. First, it must have a large positive 
slope, in the neighborhood of the pre-1700 consumption level. Second, for high levels of average consumption, the slope of the function must be near zero. The first property is only relevant for the theory of the pre-1700 era. The second property is only relevant for the theory of the post1900 period. This is the approach that we take in this essay.

With this in mind, we proceed with a neoclassical formulation of the classical theory of constant living standards. There is a single good in the model that can be used for either consumption or investment purposes. The good is produced using a constant returns to scale technology that uses capital, labor, and land. An infinitely lived household owns the economy's land and capital and rents them to firms in the economy. Land is fixed and does not depreciate. The household is made up of many members, each of whom is endowed with one unit of time. The household uses its capital, labor, and land income for consumption and investment purposes. The growth rate of population is a function of average consumption of household members. A household member's utility in the period is defined over the member's consumption in the period. The household's objective is to maximize the sum of each member's utility. The details of the economy are described as follows.

\section{Technology}

The classical theory of production is given by a Cobb-Douglas technology,

$$
Y_{M t}=A_{M t} K_{M t}^{\phi} N_{M t}^{\mu} L_{M t}^{1-\phi-\mu} .
$$

In equation (2.1), $Y_{M t}$ is output, $K_{M t}$ is capital, $N_{M t}$ is labor, and $L_{M t}$ is land in period $t$. The parameter $A_{M t}$ is total factor productivity (TFP), parameter $\phi$ is capital share, and parameter $\mu$ is labor share. The Cobb-Douglas assumption implies unit elasticity of substitution. ${ }^{5}$ We allow for

\footnotetext{
${ }^{5}$ The precise value of the elasticity of substitution between land and the other factors is not important provided that it is not greater than one. The evidence is that throughout most of history the substitution of these other factors for
} 
exogenous growth in TFP. More specifically, we assume that technology grows at the exogenous rate of $\gamma_{M}$; that is, $A_{M t}=A_{M 0}\left(1+\gamma_{M}\right)^{t}$. This assumption reflects the fact that technological change was evident from 2000 B.C. ${ }^{6}$

Output can be used for either consumption or investment purposes. The resource constraint for the economy is given by

$$
C_{t}+X_{t}=Y_{M t}
$$

where $C_{t}$ denotes total consumption and $X_{t}$ denotes total investment.

\section{Preferences}

Household preferences are added to the classical theory of production as follows. Period utility of each household member is defined over the member's consumption of the final good. We assume a log utility function, because it is in the class of utility functions that is consistent with a constant-growth equilibrium and because empirically it is consistent with a wide variety of micro and macro observations. Household utility in each period is the sum of each individual member's utility in the period. Strict concavity of individual household members' preferences implies that the household's utility is maximized by giving equal consumption to each member. For this reason, the discounted stream of utility of the household is just

$$
\sum_{t=0}^{\infty} \beta^{t} N_{t} \log \left(c_{t}\right)
$$

land was limited, and, if anything, this elasticity of substitution was less than one. The unit elasticity assumption is made because it simplifies the analysis.

${ }^{6}$ We follow Hansen and Prescott's convention of using the letter $M$ to index variables associated with the classical production function. 
where $\beta$ is the time discount factor, $c_{t}$ is consumption of a household member, and $N_{t}$ is household size.

As is evident from equation (2.3), we are using a dynastic construct. This is in contrast to Hansen and Prescott (2002), who use a two-period overlapping generations construct. We adopt an infinitely lived household framework rather than the two-period overlapping generations framework for two reasons. First and foremost, the empirical counterpart of a period is a year in the dynamic construct, while in the two-period overlapping generations construct the empirical counterpart of a period is 35 years. For the purpose of examining the model's ability to account for the large increases in output realized in a short period of time after 1950 by countries such as Japan and South Korea, 35 years is simply too long a period to study.

Second, the size of the effect on a country's steady state level of per capita output associated with policies that determine its savings rate is sensitive to the construct that is used. The tax rate system of a country is an example of such a policy. The level effects associated with this type of policy are in fact larger with the dynastic construct. This fact is important for judging whether differences in savings rates can account for the large differences in transition dates. If plausible differences in savings rates fail to give rise to 200 -year delays in development in the dynastic construct, then they also fail to give rise to this delay in the overlapping generations framework, and we can conclude that some factor other than savings rates accounts for the pattern of development. ${ }^{7}$ This is essentially the finding of the quantitative exercises undertaken by Parente and Prescott (2000). The choice of construct is irrelevant, however, in assessing the plausibility of other factors such as efficiency, as reflected in TFP differences: the

\footnotetext{
${ }^{7}$ See Hendricks (2003) for a more detailed explanation of this phenomenon.
} 
size of the level effects is the same regardless of whether the dynastic or overlapping generations construct is employed.

\section{Endowments}

Each member of the household is endowed with one unit of time, which the member can supply to firms in the economy to earn wage income. The household is also endowed with the economy's stock of land and capital, which the household rents to firms. Land in the economy is fixed in supply: it cannot be produced, and it does not depreciate. Without loss of generality, the total quantity of land in the economy is normalized to one. Since land has no alternative use aside from production, the input to production in each period is one. Capital is assumed to depreciate and evolves according to the following law of motion:

$$
K_{t+1}=(1-\delta) K_{t}+X_{t}
$$

where $\delta$ is the depreciation rate.

\section{Population Dynamics}

As mentioned earlier, because we take a societal approach to population size, we model population growth as a function of the average consumption level of household members. More specifically, we assume that the number of members born into a household in period $t+1$ depends on the average consumption level of household members from period $t$. Let $N_{t}$ denote the number of household members in period $t$, and let $c_{t}$ denote their average consumption level. Then,

$$
N_{t+1}=g\left(c_{t}\right) N_{t}
$$

The function $g$ is the growth factor of population from one period to the next. The classical prediction of a stable living standard at the pre-1700 level, $c_{M}$, requires that the function $g$ have a 
sufficiently large and positive slope at $c_{M}$. This $c_{M}$ is the maximal living standard consistent with a society being able to defend its land.

\section{Equilibrium Properties}

For such a population growth function, there is a steady-state equilibrium with a constant living standard $c_{M}$ and a population growth rate equal to $\left(1+\gamma_{M}\right)^{1 /(1-\phi-\mu)}-1$. This constant living standard satisfies $g\left(c_{M}\right)=\left(1+\gamma_{M}\right)^{1 /(1-\phi-\mu)}$. Were the living standard to rise above $c_{M}$, say, because of plague or drought, population increase would exceed technological advances and the living standard would then fall until it returned to $c_{M}$. If for some reason $c$ were below $c_{M}$, the population growth factor would be less than the one needed to maintain the living standard, and the living standard would increase until it was again $c_{M}$. Along the steady-state equilibrium path, aggregate output, capital, consumption, and the rental rate of land all grow at the rate of the population. Per capita variables as well as the rental price of labor and capital are all constant. Increases in technology in this model simply translate into a higher population rather than higher living standards. This is precisely the pattern of development observed prior to 1700 .

\section{B. Modern Growth Theory: The Post-1900 Era}

The classical theory accounts well for the pattern of economic development up to 1700 . However, it does not account for the increase in living standards that occurred after 1900. Since about 1900, the growth rate of the early developers has been roughly constant, with a doubling of per capita output every 35 years. Modern growth theory, in contrast, does account for the increase. In addition to the roughly constant rate of growth achieved by developed countries over the last century and a half, other facts characterize modern economic growth. These facts are roughly that the consumption and investment shares of output are constant, the share of income 
paid to capital is constant, the capital-to-output ratio is constant, and the real return to capital is constant.

Modern growth theory accounts well for these modern growth facts. Quantitatively, the steady-state equilibrium of the economy mimics the long-run observations of the United Kingdom and the United States. This is no surprise: Solow (1970) developed the theory with these facts in mind. A key feature of that theory is a Cobb-Douglas production function that includes no fixed factor of production and that is subject to constant exogenous technological change. More specifically, the production technology for the composite good that can be used for either consumption or investment purposes is given by

$$
Y_{S t}=A_{S t} K_{S t}^{\theta} N_{S t}^{1-\theta}
$$

In equation (2.6), $Y_{S t}$ is output, $K_{S t}$ is capital, and $N_{S t}$ is labor in period $t$. The parameter $\theta$ is capital share, and the parameter $A_{S t}$ is TFP, which grows exogenously at the constant, geometric rate $\gamma_{s}$. As can be seen, the critical difference between the traditional and modern growth production functions is that the modern growth function does not include the fixed factor input, land. $^{8}$

Because the final objective of this section is to merge the classical theory and the modern growth theory into a single model, we maintain the same assumptions regarding preferences, endowments, and population dynamics as in the preceding subsection. The household in the model rents capital to firms and supplies labor. It uses its capital and labor income to buy consumption for household members and to augment the household's stock of capital.

\footnotetext{
${ }^{8}$ Again, we follow Hansen and Prescott's convention of using $S$ to index variables associated with the modern growth production function.
} 
In contrast to the classical theory, population growth in the modern theory does not have any consequences for the growth rate of per capita variables in the long run. The choice of the population growth function is therefore unimportant in this respect. The standard procedure is to assume a population growth function $g(c)$ that is constant over the range of sufficiently high living standards associated with the modern growth era. Population thus grows at a constant exponential rate.

Clearly, population cannot grow at an exponential rate forever. At some population level, natural resources would become a constraining factor. If population were ever to reach this level, it would be unreasonable to abstract from land as a factor of production. But societies control their population so that it never reaches this level. Indeed, reproduction rates have fallen dramatically in the last 50 years, so much in the rich countries, in fact, that these countries must increase their fertility rates to maintain their population size in the long run. This suggests a population growth function that asymptotically approaches one.

In the case where the population growth function is a constant, per capita output, consumption, and capital all increase at the rate $\left(1+\gamma_{S}\right)^{1 /(1-\theta)}$ along the equilibrium constant growth path. The rental price of labor also grows at this rate. The rental price of capital, in contrast, is constant. Capital's share of income is also constant and equal to $\theta$, as is consumption's share and investment's share of output. As can be seen, the growth rate of the economy's living standard is independent of the economy's population growth rate: the only thing that matters is the exogenous growth rate of technological change. The population growth rate does have an effect on the level of per capita output along the constant growth path, but it is small. Thus, unlike in the model of the pre-1700 era, the population growth function in the model of the post-1900 era plays only a minor role. 


\section{C. The Combined Theory}

The classical theory accounts well for the constant living standard that characterizes the pre-1700 era, and the modern growth theory accounts well for the doubling of living standards every 35 years that characterizes the post-1900 experience of most of the currently rich, large, industrialized countries. In the period in between, living standards increased in these countries, but at a slower and far more irregular rate compared to the post-1900 period.

We seek a theory of this development process, namely, a theory that generates a long period of stagnant living standards up to 1700 , followed by a long transition, followed by modern economic growth. Given the success of the classical theory and the modern growth theory in accounting for the pre-1700 and post-1900 eras, the logical step, and the one taken by Hansen and Prescott (2002), is to merge the two theories by permitting both technologies to be used in both periods. We now present the combined theory of Hansen and Prescott, and use that theory to organize and interpret the development path of the leading industrialized country over the 1700-2000 period.

In the combined theory of Hansen and Prescott (2002), output in any period can be produced using the traditional or the modern growth production function or both. Both technologies, therefore, are available for firms to use in all periods. ${ }^{9}$ Capital and labor are not specific to either production function. In light of these assumptions, the aggregate resource constraint for the combined model economy is

$$
N_{t} c_{t}+X_{t} \leq Y_{M t}+Y_{S t}=Y_{t} \text {, }
$$

the capital rental market-clearing constraint is

\footnotetext{
${ }^{9}$ The maximum output that can be produced if both technologies are available is characterized by a standard aggregate production function $Y_{t}=A_{t} F\left(K_{t}, L_{t}, N_{t}\right)$. By standard we mean that it is weakly increasing and concave, homogeneous of degree one, and continuous. Even though both the Malthus and the Solow production functions are Cobb-Douglas technologies, the function $F$ is not Cobb-Douglas.
} 


$$
K_{t}=K_{M t}+K_{S t},
$$

and the labor market-clearing condition is

$$
N_{t}=N_{M t}+N_{S t} .
$$

Household preferences continue to be given by equation (2.3). Additionally, the population growth function continues to be given by equation (2.5), and it displays the properties that the function has a large positive slope in the neighborhood of the pre-1700 consumption level and a slope near zero for large levels of consumption.

In their combined theory, Hansen and Prescott assume that the growth rate of TFP for the traditional production function and the growth rate of TFP for the modern economic growth production function are each constant over time. We deviate from Hansen and Prescott on this dimension. Although we maintain their assumption that the rate of TFP growth associated with the traditional technology is constant, we assume that the rate of TFP growth associated with the modern growth technology increases over time, converging asymptotically to the modern growth rate. We make this alternative assumption in light of the empirical counterparts of the two production functions and the historical evidence on technological change.

The empirical counterpart of the classical production function is a traditional technology for producing goods and services that is most commonly associated with the family farm. A key feature of this production technology is that it is based on the use of land in the production of hand tools and organic energy sources. For this technology, the historical record shows gradual improvements in these methods over the last 2,000 years at a roughly constant rate of change. ${ }^{10}$ The empirical counterpart of the modern growth production function is a modern technology that

\footnotetext{
${ }^{10}$ The exception to this constant rate of growth might be the Green Revolution in the middle of the twentieth century, where the introduction of new seed varieties resulted in large increases in farm yields associated with traditional farming methods.
} 
is most commonly associated with the factory. ${ }^{11}$ A key feature of this technology is that it uses machines driven by inanimate sources of energy. For this technology, the historical record suggests modest growth in the eighteenth century, followed by much higher growth in the nineteenth and twentieth centuries. Lighting, communication, and transportation were important areas where this accelerating pattern occurred. Consequently, a more plausible assumption is that the growth of TFP associated with the modern production function increased slowly after 1700 and converged to the rate associated with the modern growth era shortly after 1900.

We emphasize that the traditional sector should not be thought of as primarily the agricultural sector, though most outputs of this sector are agricultural products. What characterizes the traditional sector is that the household is the producing unit and typically consumes much of what it produces. Sugar plantations in the Caribbean and cotton plantations in the United States were not part of the traditional sector. There was little incentive for people working in the traditional sector to develop more efficient production methods. Rapid increases in agricultural productivity occurred only when goods developed in the industrial sector were introduced in farming. The reaper and the tractor dramatically increased productivity on farms. Insecticides and fertilizers also contributed to productivity, as did the development of hybrid corn and new seeds. This is all well-documented by Johnson (2000).

An economy that starts out using only the traditional production function will eventually use the modern one. To see this, suppose that it were never profitable for firms to use the modern production function. Then the economy's equilibrium path would converge to the steady state of the pre-1700-only model. The steady state of that model is characterized by constant rental prices

\footnotetext{
${ }^{11}$ The distinction between technologies is, thus, not along the lines of agriculture and manufactures. In this classification, modern agriculture with its use of synthetic fertilizers and tractors is associated with the modern growth production function.
} 
for capital and labor, $r_{M}$ and $w_{M}$. Capital and labor are not specific to any one technology. Thus, a firm that first considers using the modern production function can hire any amount of capital and labor at the factor rental prices $r_{M t}$ and $w_{M t}$. Profit maximization implies that a firm will not choose to operate the modern growth technology if

$$
A_{S t}<\left(\frac{r_{M t}}{\theta}\right)^{\theta}\left(\frac{w_{M t}}{1-\theta}\right)^{1-\theta} .
$$

This inequality must be violated at some date. Asymptotically, the rental prices would approach constant values if only the traditional production function were operated, and so the right-hand side of (2.10) is bounded. The left-hand side is unbounded because TFP in the modern function grows forever at a rate bounded uniformly away from zero. The inequality given by (2.10), therefore, must eventually be violated.

At the date when TFP in the modern production function surpasses the critical level given by the right-hand side of (2.10), the economy will start using the modern growth production function. This marks the beginning of the Industrial Revolution. This result is independent of the size differences in the growth rates of TFP associated with the traditional and modern production functions. Over the transition, more and more capital and labor will be moved to the modern production sector. The traditional production function will, however, continue to be operated, though its share of output will decline to zero over time. This follows from the assumptions that land is used only in traditional production and that its supply is inelastic.

We now use the combined theory to organize and interpret the development path of the industrial leader over the 1700-2000 period. The empirical counterpart of a period is a year. The initial period of the model is identified with the year $1675 .{ }^{12}$ We attribute the stagnation of the

\footnotetext{
${ }^{12}$ There is nothing special about the choice of 1675. None of the results would change if the initial period were identified with some other year. Only the value of $A_{S 0}$ would change in the experiments.
} 
leader prior to 1700 to an insufficiently low level of TFP associated with the modern production function to warrant its use. We attribute the start of economic growth of the leader in 1700 to growth in TFP associated with the modern production function so that its level exceeds the critical value given by equation (2.10). Lastly, we attribute the rising rate of growth of per capita output of the leader from 1700 to 1900 to greater use of the modern production function and the rising rate of growth of TFP.

We proceed to parameterize the model. The model is calibrated so that the economy starts to use the modern production function in 1700. Following Hansen and Prescott (2002), we calibrate the model so that the steady state of the classical-only model (subsection 2A) matches pre-1700 observations and the steady state of the modern growth-only model (subsection 2B) matches the post-1900 growth experience of the United States.

In the calibration, we deviate from Hansen and Prescott along two dimensions. First, we calibrate the population growth function so that it matches Maddison's (1995) estimates for U.K. population growth rates over subperiods of the $1675-1990$ period. ${ }^{13}$ Given our theory of population growth, it is more appropriate to use the time series data from a particular country to restrict the population growth function for that country rather than cross-section data as Hansen and Prescott do. ${ }^{14}$ Second, we calibrate the annual growth rate of TFP for the modern production function so that it remains at the traditional rate up until 1700, increases linearly to reach onehalf of its modern growth rate in 1825 , and then increases linearly to reach its modern growth rate in 1925.

\footnotetext{
${ }^{13}$ The calibration assumes constant population growth after 1973 equal to the average annual population growth of the United Kingdom from 1973 to 1994.

${ }^{14}$ We do not use the U.S. population growth rate data in the calibration. Doing so would not change any of the results because the population growth rate function is not important in the modern growth era.
} 
Following Hansen and Prescott, we pick the initial capital stock and the initial population so that if only the traditional production function were available, the equilibrium would correspond to the steady state of the pre-1700 model, and there would be no incentive to operate the modern production function if it were available. This ensures that in period 0 only the traditional production function is operated and that there is a period of constant living standards. Table 1 lists the values for each of the model parameters and provides comments where appropriate. The population growth rate function implied by the U.K. population growth data used in the computation is depicted in Figure 3.

For the parameterized model economy, it takes 150 years before 95 percent of the economy's output is produced in the modern sector. Figures 4-6 depict the model economy's development path along a number of dimensions. Figure 4 compares period $t$ per capita output relative to 1700 per capita output for the model economy and the industrial leader as reported by Maddison (1995, Tables 1.1 and C.12). According to the model, an economy that begins the transition in 1700 will be approximately 28 times richer in 1990 than in 1700. Figure 5 depicts the growth rate of per capita output for the model economy over the 1700-2000 period. The growth rate of per capita output is slow at the onset of the transition, less than 1 percent per year on average before 1825 . By 1900 the growth rate is near the modern growth rate of 2 percent per year. This pattern is primarily a consequence of the assumption that TFP growth for the modern technology increases slowly over the 1700-1900 period. Figure 6 depicts the path of the rental prices of capital and labor over the 1700-2000 period. As can be seen, the real wage rate increases steadily once the transition begins. The real interest rate, in contrast, shows very little secular change over three centuries. These latter predictions conform well to the pattern of development associated with England, the United States, and other early developers. 
Table 1. Restricted Parameter Values

\begin{tabular}{|c|c|c|}
\hline Parameter & Value & Comment \\
\hline $\begin{array}{l}\gamma_{M} \text {-growth rate of TFP for } \\
\text { traditional production }\end{array}$ & .0009 & $\begin{array}{l}\text { Consistent with pre-1700 world } \\
\text { population average annual growth rate } \\
\text { of } .003\end{array}$ \\
\hline $\begin{array}{l}\phi \text {-capital share in } \\
\text { traditional production }\end{array}$ & .10 & $\begin{array}{l}\text { Consistent with pre-1700 estimates of } \\
\text { land's share reported by Clark (1998) } \\
\text { and Hoffman (1996) }\end{array}$ \\
\hline $\begin{array}{l}\mu \text {-labor share in traditional } \\
\text { production }\end{array}$ & .60 & $\begin{array}{l}\text { Chosen so that labor's share does not } \\
\text { vary with the level of development as } \\
\text { reported by Gollin (2002) }\end{array}$ \\
\hline $\begin{array}{l}A_{M O}-\text { initial TFP for } \\
\text { traditional production }\end{array}$ & 1.0 & Normalization \\
\hline$\delta$-depreciation rate & .06 & $\begin{array}{c}\text { Consistent with U.S. capital stock and } \\
\text { investment rate since } 1900\end{array}$ \\
\hline $\begin{array}{l}\gamma_{s}-\text { asymptotic TFP growth } \\
\text { rate for modern production }\end{array}$ & .012 & $\begin{array}{l}2 \text { percent rate of growth of per capita } \\
\text { GDP in modern growth era }\end{array}$ \\
\hline $\begin{array}{l}\theta \text {-capital's share in modern } \\
\text { production }\end{array}$ & .40 & U.S. physical capital's share of output \\
\hline $\begin{array}{l}A_{S O} \text {-initial TFP for modern } \\
\text { production }\end{array}$ & .53 & $\begin{array}{l}1700 \text { starting date given initial period } \\
\text { for model is } 1675\end{array}$ \\
\hline $\begin{array}{l}\beta \text {-subjective time discount } \\
\text { factor }\end{array}$ & .97 & $\begin{array}{l}\text { Consistent with real rate of interest } \\
\text { between } 4 \text { and } 5 \text { percent in modern } \\
\text { growth era }\end{array}$ \\
\hline
\end{tabular}

The predictions of the model are not sensitive to the value of the capital share parameter in the modern growth production function. This is an important result, because the magnitude of the capital share with a broad definition of capital that includes intangible as well as tangible capital could well be greater than the 0.40 share value used in the above exercise. The paths of per capita GDP, its growth rate, and rental prices are nearly identical to those shown in Figures 4-6 for alternative values of the capital share in the modern production function. The transition still takes a long time. For a capital share as high as $0.70,140$ years elapse before 95 percent of the economy's capital is produced using the modern production function. 


\section{A Theory of Relative Efficiencies}

The Hansen and Prescott (2002) theory of economic development reviewed in Section 2 is not a theory of the evolution of international income levels. It does not address the issue of why modern economic growth started at different dates in different countries. India, for example, began modern economic growth nearly 200 years later than did the United Kingdom. As a result, India's income level relative to the leader fell from 50 percent in 1770 to only 5 percent in 1970. Neither does the theory address the issue of why some countries that have been experiencing modern economic growth for a century or more have failed to narrow the income gap with the industrial leader. In Latin American countries, for example, income levels have remained at roughly 25 percent the U.S. income level since the second half of the nineteenth century when modern economic growth began there. The theory does not address the issue of why some countries in the 1950-2000 period have been able to substantially narrow the income gap with the industrial leader. These countries include Italy, Spain, Japan, Korea, and Taiwan, the latter three all of which experienced a growth miracle. Some factor that differs across countries must be added to the Hansen and Prescott theory to make it a theory of the evolution of international income levels.

One might be led to introduce differences in TFP associated with the modern production function to the model, because the Hansen and Prescott theory of development predicts that per capita income in a country starts to increase once TFP in the modern sector reaches a critical level. Moreover, there is ample evidence that countries (at least those experiencing modern economic growth) differ along this dimension. ${ }^{15}$ Although it would be easy to introduce such differences into the Hansen and Prescott theory, it would not be useful, as long as country-

\footnotetext{
${ }^{15}$ See, for example, Klenow and Rodriguez-Clare (1997), Hall and Jones (1999), and Hendricks (2002).
} 
specific TFP differences are treated exogenously. Absent a theory of country-specific TFP, the theory of the evolution of international income levels is sterile because it offers no policy guidance. What is needed is a policy-based theory of why TFP differs across countries at a point in time.

Parente and Prescott (2000) develop a theory of TFP that attributes differences in TFP to country-specific policies that both directly and indirectly constrain the choice of production units. Their theory of TFP is more appropriately called a theory of relative efficiencies. This is because Parente and Prescott (2000) decompose a country's TFP into the product of two components. The first component is a pure knowledge or technology component, denoted by $A$. The second is an efficiency component, denoted by $E$. In the context of the Hansen and Prescott model, the modern growth production function is

$$
Y_{S t}=E_{S} A_{S t} K_{S t}^{\theta} N_{S t}^{1-\theta} .
$$

The technology component of TFP, $A_{S t}$, is common across countries. It is the same across countries because the stock of productive knowledge that is available for a country to use does not differ across countries. ${ }^{16}$ The efficiency component differs across countries as the result of differences in economic policies and institutions. Here we consider the case in which a country's economic policies and institutions do not change over time, so $E_{s}$ is not subscripted by $t$. The efficiency component is a number in the $(0,1]$ interval. An efficiency level less than one implies that a country operates inside the production possibilities frontier, whereas an efficiency level equal to one implies that a country operates on the production possibilities frontier. Differences in efficiency, therefore, imply differences in TFP.

\footnotetext{
${ }^{16}$ Much of the stock of productive knowledge is public information, and even proprietary information can be accessed by a country through licensing agreements or foreign direct investment.
} 
Relative efficiencies at a point in time, and not absolute efficiencies, can be determined using the production function and the data on quantities of the inputs and the output. Thus, it is not possible to determine if any country has an efficiency level equal to one, although we tend to doubt that this is the case. Changes in relative efficiencies of a given country can also be determined conditional on an assumption on the behavior of the technology component of TFP such as that it grows at some constant rate.

We now present the Parente and Prescott (2000) theory of relative efficiencies. To keep the analysis manageable, we present the theory of relative efficiencies in the context of an economy in which only the modern production function is available. The theory constitutes a theory of the aggregate production function when there are constraints at the production unit level.

In light of this, we first review the theory underlying the aggregate production function. We then show how policy constraints give rise to an aggregate production function with a different efficiency level. We follow this by providing estimates of cross-country relative efficiencies associated with the modern production function using the mapping from policy to aggregate efficiency derived in this section with estimates of the costs imposed by a countryspecific policy. Finally, we conclude this section with a discussion of why constraints on the behavior of the production units exist.

\section{The Aggregate Production Function}

Before developing the mapping from policy to aggregate efficiency, we briefly review the theory of the aggregate production function associated with modern growth. The theory underlying the aggregate production function is as follows. In each period, there is a set of plant technologies $B$. A plant technology $b \in B$ is a triplet that gives the plant's output $y_{b}$ and its 
capital and labor inputs, $k_{b}$ and $n_{b}$. A plan $\left\{\lambda_{b}\right\}$ specifies the measure of every type of plant operated. The aggregate production function, that is, the maximum $Y$ that can be produced given aggregate inputs $K$ and $N$, is

$$
Y=F(K, N)=\max _{\lambda \geq 0} \sum_{b} \lambda_{b} y_{b}
$$

subject to the two resource constraints

$$
\begin{aligned}
& \sum_{b} \lambda_{b} k_{b} \leq K \\
& \sum_{b} \lambda_{b} n_{b} \leq N .
\end{aligned}
$$

Assuming that this program has a solution, which it will under reasonable economic conditions, the aggregate production function will be weakly increasing, weakly concave, homogeneous of degree one, and continuous.

Empirically, the Cobb-Douglas aggregate production function is the one consistent with the post-1900 modern economic growth era. The question then is, What set of technologies $B$ gives rise to the Cobb-Douglas aggregate production function? One such set is the set of plant technologies defined by

$$
y \leq d(n) k^{\theta} .
$$

The function $d(n)$ is an increasing and continuous function of the labor input. Assuming that $n^{*}=\arg \max d(n) n^{\theta-1}$ exists, the aggregate production function is

$$
Y=A K^{\theta} N^{1-\theta}
$$

where $A=\max d(n) n^{\theta-1}$. A sketch of the proof is as follows. If any quantity of capital and labor is allocated to a single type plant in such a way that output is maximized, then the number of employees at each plant is $n^{*}$. Thus, all operated plants, for an optimum, must have $n^{*}$ workers. Given $\theta<1$, the capital stock must be allocated in equal quantity over every operated 
plant. Thus, the number of plants operated is $N / n^{*}$, capital per operated plant is $K /\left(N / n^{*}\right)$, the number of workers per operated plant is $n^{*}$, and maximal output is given by (3.6). With the assumption that the function $d$ increases over time, the expression $A$ will increase over time.

\section{Consequences of Constraints for Aggregate Efficiency}

Next, consider the plant production technology with constraints imposed on it. We consider two types of policy. The first type constrains how a particular plant technology can be operated. The second type constrains the choice of which plant technologies can be operated. Certainly, these are not the only type of constraints that will affect a country's TFP. A number of other types of policy have a similar effect. ${ }^{17}$

The first type of policy constrains how a given technology is operated. A policy that gives rise to this type of constraint is a work rule, which dictates the minimum number of workers or machines needed to operate a plant technology. In particular, suppose constraints are such that the input to a $b=(k, n, y)$ type plant must be $\phi_{K} k_{b}$ and $\phi_{N} n_{b}$ for all plant types where $\phi_{K}$ and $\phi_{N}$ each exceed one. This implies that a particular technology, if operated, must be operated with excessive capital and labor. With these constraints, the aggregate production function is

$$
Y=E_{S} A K^{\theta} N^{1-\theta}
$$

where $E_{S} \equiv \phi_{K}^{-\theta} \phi_{N}^{\theta-1}$. This is the aggregate production function used in Section 2. If the nature of the constraints were to double the capital and labor requirements, then the efficiency measure would be one-half. If the nature of the constraints is to quadruple both the capital and labor requirements, then the efficiency measure would be one-fourth.

\footnotetext{
17 For example, Schmitz (2001) suggests a mapping from government subsidies to state-owned enterprises to aggregate efficiency.
} 
The second type of policy constrains the choice of which plant technologies can be operated. This type of constraint maps into the efficiency parameter of an aggregate production function with a composite capital stock made up of both physical and intangible components. Any policy that serves to increase the amount of resources the production unit must spend in order to adopt a better technology is a constraint of this nature. Such policies and practices take the form of regulation, bribes, and even severance packages to factor suppliers whose services are eliminated or reduced when a switch to a more productive technology is made. In some instances, the policy is in the form of a law that specifically prohibits the use of a particular technology. The empirical evidence suggests that this second type of constraint is more prevalent than the first. ${ }^{18}$

Following Parente and Prescott (2000), let the output of a quality $b$ plant be given by the following equation:

$$
y_{t}=b k_{P t}^{\theta_{P}}\left[\min \left(n_{t}, \bar{n}\right)\right]^{\theta_{n}} \quad \bar{n}>0, \quad \theta_{P}<1 .
$$

With this technology, a minimum number of workers, $\bar{n}$, is required to operate a plant. The variable $k_{P}$ denotes the physical capital input. The subscript $P$ is introduced in order to differentiate physical capital from intangible capital later in the analysis. There are no increasing returns to scale in the economy, because if the inputs of the economy are doubled, the number of plants doubles. ${ }^{19}$

A plant's quality is a choice variable. To improve its quality, resources are needed. This resource cost is the product of two components. The first component is technological in nature and reflects the cost in the absence of constraints. The second component, denoted by $\phi_{I}>1$,

\footnotetext{
${ }^{18}$ See Parente and Prescott (2000) for a survey of this evidence.

${ }^{19}$ See Hornstein and Prescott (1993) for a detailed coverage of this technology.
} 
reflects the constraint itself. The function that gives the required resources a plant must expend to advance its quality from $b$ to $b^{\prime}$ is

$$
x_{b b^{\prime}}=\phi_{I} \int_{b}^{b^{\prime}}\left(\frac{s}{W_{t}}\right)^{\alpha} d s
$$

Here $W_{t}$ is the stock of pure knowledge in the world in period $t$. Its growth rate is exogenous and equal to $\gamma_{W}$. Thus,

$$
W_{t}=W_{0}\left(1+\gamma_{W}\right)^{t}
$$

Integrating (3.9) and defining $x_{I t}=x_{b b^{\prime}}$ yields

$$
x_{I t}=\phi_{I} \frac{b_{t+1}^{\alpha+1}-b_{t}^{\alpha+1}}{W_{0}^{\alpha}\left(1+\gamma_{W}\right)^{\alpha t}(1+\alpha)} .
$$

Let

$$
k_{I t}=\frac{\phi_{I} b_{t}^{\alpha+1}}{W_{0}^{\alpha}\left(1+\gamma_{W}\right)^{\alpha(t-1)}(1+\alpha)} .
$$

The variable $k_{I t}$ has the interpretation of the plant's intangible capital stock; it is the value of the plant's past investments in quality improvements. The plant technology is specified by

$$
y_{t}=\mu \phi_{I}^{-\theta_{I}}\left(1+\gamma_{W}\right)^{\alpha \theta_{I} t} k_{I t}^{\theta_{I}} k_{P t}^{\theta_{P}}\left[\min \left(\bar{n}, n_{t}\right)\right]^{\theta_{n}},
$$

with

$$
k_{I t+1}=\left(1-\delta_{I}\right) k_{I t}+x_{I t},
$$

where $\delta_{I}$ and $\mu$ are functions of $\alpha, \gamma_{W}$, and $W_{0}$, and $\theta_{I}=1 /(1+\alpha)$. The sum of $\theta_{I}$ and $\theta_{P}$ is strictly less than one, so there is an optimal plant size, with all operated plants having $n^{*}$ workers and equal amounts of both capital stocks.

Aggregating over plants implies the following equilibrium aggregate production relation: 


$$
Y_{t}=E_{S} A_{0}\left(1+\gamma_{S}\right)^{t} K_{I t}^{\theta_{I}} K_{P t}^{\theta_{P}} N_{t}^{1-\theta_{P}-\theta_{I}}
$$

with $E_{S} \equiv \phi_{I}^{-\theta_{I}}$ and $\left(1+\gamma_{S}\right)=\left(1+\gamma_{W}\right)^{\alpha \theta_{I}}$. The laws of motion for the aggregate capital stocks are

$$
K_{I, t+1}=\left(1-\delta_{I}\right) K_{I t}+X_{I t}
$$$$
K_{P, t+1}=\left(1-\delta_{P}\right) K_{P t}+X_{P t},
$$

where $\left(1-\delta_{I}\right)=1 /\left(1+\gamma_{W}\right)^{\alpha}$.

Now if intangible capital has the same depreciation rate as physical capital, then the model with these two capital stocks is isomorphic to the model of subsection $2 \mathrm{~B}$ with a single capital stock. The single capital stock, $K_{t}$, is a composite of the intangible and physical capital stocks where

$$
\begin{aligned}
& K_{I t}=\frac{\theta_{I}}{\theta_{I}+\theta_{P}} K_{t} \\
& K_{P t}=\frac{\theta_{P}}{\theta_{I}+\theta_{P}} K_{t} .
\end{aligned}
$$

The capital share in the single capital stock model, $\theta$, is just the sum of $\theta_{I}$ and $\theta_{P}$, and investment in the single capital stock model, $X_{t}$, is just the sum of the investments in physical and intangible capital, $X_{I t}+X_{P t}$.

For the sake of consistency and brevity, we continue to use the model economy with a single capital stock in our presentation of the unified theory of the evolution of international incomes. In those instances where we wish to consider the role of intangible capital, we proceed by assigning a value to the capital share parameter in the modern production function that exceeds 0.40 , the share of physical capital's output in the national income accounts. We solve out the model economy with a single capital stock and then impute the intangible and physical capital components, as well as their investments. This can effectively be done using equations 
(3.16) and (3.17) given a decomposition of the total capital share into its intangible and physical components. $^{20}$

\section{Estimates of Aggregate Relative Efficiency}

The mappings developed in the preceding subsection allow us to impute the aggregate relative efficiency associated with the modern production function for various constraints. In general, the size of the effect of the constraint on a country's aggregate efficiency depends on the factor input affected by the constraint and on that input's share in the production function. In the special case where the constraints affect all inputs equally, that is, $\phi=\phi_{n}=\phi_{I}=\phi_{P}$, the individual factor shares are unimportant and the efficiency level of a country is just $E_{s}=\phi$. Hence, the implied difference in relative efficiencies is equal to the implied cost differences of policy. Thus, if the cost difference in policies between two countries is a factor of five, the implied factor difference in aggregate relative efficiency is also five.

Are factor differences in relative efficiency greater than five reasonable? Obviously, it is not possible to answer this question definitively without a comprehensive international study of the total costs of the constraints imposed by society. Some estimates of the cost differences associated with some country-specific policies do exist. Studies that estimate the costs of certain policies of individual countries that affect the technology and work practice choices of the production units located there do find that these costs vary systematically with income levels, with large differences existing between rich and poor countries. These studies suggest that factor differences in relative efficiencies could easily be as great as five.

\footnotetext{
${ }^{20}$ We say effectively because there are two technical issues in the combined theory when capital is broadly defined. First, if intangible capital is not an input into the traditional production function, then the economy will need to make some investments specifically in intangible capital prior to switching to the modern production function. Second, after the transition, as new plants open, they will have a lower technology level compared to older plants.
} 
For example, Djankov et al. (2002) calculate the costs associated with the legal requirements in 75 countries that an entrepreneur must meet in order to start a business. They find that the number of procedures required to start up a firm varies from a low of 2 in Canada to a high of 20 in Bolivia and that the minimum official time required to complete these procedures ranges from a low of 2 days in Canada to a high of 174 days in Mozambique. These costs do not reflect any unofficial costs involved with starting a firm, such as bribes or bureaucratic delays. Because these official cost measures are positively correlated with indexes that incorporate measures of bribes, the true difference in start-up costs between low-cost and high-cost countries is surely even larger than those reported in the study.

\section{Reasons for Constraints}

The evidence strongly suggests that production units in poor countries are severely constrained in their choices, and the costs associated with these constraints are large. This prompts the question, Why does a society impose these constraints? A large number of studies, some of which are surveyed in Parente and Prescott (2000), suggest that constraints typically are imposed on firms in order to protect the interests of factor suppliers to the current production process. These groups stand to lose in the form of reduced earnings if new technology is introduced. These losses occur because either the input they supply is specialized with respect to the current production process or the monopoly power granted to them over the supply of a particular input is eroded. ${ }^{21}$

\footnotetext{
${ }^{21}$ Parente and Prescott (1999) show in a model with no capital how a monopoly right granted to factor suppliers can significantly lower a country's efficiency. Herrendorf and Teixeira (2003) extend this model to include physical capital and show that these monopoly rights have even larger effects on a country's efficiency.
} 


\section{A Unified Theory of the Evolution of International Incomes}

In this section we unify the Parente and Prescott (2000) theory of relative efficiencies and the Hansen and Prescott (2002) theory of development. The unified theory is then used to organize and interpret the evolution of international income levels. We unify the Parente and Prescott (2000) theory and the Hansen and Prescott theory as follows. We assume that technological level increases in both sectors result from growth in world knowledge. Consequently, the technology component of TFP in each production function is the same across countries at any point in time. The paths for the technology components of TFP are determined as in subsection $2 \mathrm{C}$ by requiring that the leader country with an efficiency parameter in the modern sector set to one start its transition to modern economic growth in 1700 . We then introduce differences in this efficiency parameter across countries. Given a country's relative efficiency parameter and the common path of the technology components of the TFPs, we compute the equilibrium path of the economy.

As mentioned in Section 3, we doubt than any country has or had an efficiency parameter equal to one. The assumption that efficiency in the leader is one in the unified theory is not important to any of the results because it is just a normalization. Again, only relative efficiencies matter and can be determined. This is the case for countries at a given time and across time in a given country.

We do not introduce cross-country differences in the efficiency parameter associated with traditional production. As mentioned in the introduction, incomes did differ slightly prior to 1700 , with the richest countries being no more than two or three times richer than the poorest. One possible explanation for these pre-1700 differences in income levels is that countries differed in policies that increased the inputs required for producing goods with the traditional 
production function. Because this technology corresponds to traditional farming and even manufactures produced within a home setting, we think the effect of policy differences for relative efficiencies associated with traditional production is small. For this reason, we favor the alternative explanation that some countries were better able to defend themselves from outside expropriations because of geography and thus were able to maintain a higher constant living standard during the pre-1700 era. Two countries that enjoyed such an advantage were England and Japan.

We interpret delays in the start of the transition to modern economic growth to late starters having a lower relative efficiency in the modern sector, at least up until the date their transitions began. We attribute the persistent percentage difference between such a country and the industrial leader to the continuation of its low relative efficiency. Finally, we attribute catchup, including growth miracles, to large increases in relative efficiency in countries.

We begin by computing the relative efficiency of a late starter required to delay the start of its transition by a given length of time. The size of the required efficiency difference between the leader and the laggard that gives rise to any given delay is a function of the capital share parameter in the modern production function. Our main finding is that differences in relative efficiency required to generate delays in starting dates of the lengths observed in the historical data are reasonable for all capital shares above 0.40 .

We then compute the entire equilibrium path of these late starters assuming that their efficiency levels relative to the leader never change. Large differences in incomes exist even after the late starters are in the modern economic growth phase. In fact, the gap between the leader and late starters increases for some time after the laggards have started the transition to modern economic growth. This is the case even though the transition period of late starters is 
shorter than that of early starters. The main finding of these experiments is that the gap in incomes between early and late starters never narrows unless the laggard adopts polices that increase its productive efficiency.

The final set of experiments allows for a one-time increase in a country's relative efficiency parameter. We assume that the change is unexpected from the standpoint of the late starter and viewed as permanent in nature. We then compute the equilibrium path and determine the country's output relative to that of the leader subsequent to the change. We find that the late starter's path of output relative to the leader subsequent to the change in its efficiency parameter is consistent with the experience of growth miracle countries such as Japan, but only if the capital share is between one-half and two-thirds.

We conclude from this analysis that capital's share must be large for the unified theory to be a successful theory of the evolution of international income levels. A large capital share implies an important role for intangible capital in the production of goods and services and large investment in intangible capital as a fraction of GDP. Investment in intangible capital goes unmeasured in the national income and product accounts. Thus, it is not possible to determine whether a large capital share is plausible by examining national account data. One must examine other evidence, in particular, micro evidence to determine the plausibility of a large capital share. Thus, we end this section by examining the micro evidence on the size of unmeasured investment in the economy. We conclude from this evidence that the size of unmeasured investment in the economy is as large as the size predicted by the unified theory.

\section{Delays in Starting Dates}

We first examine whether the unified theory predicts large delays in the start of the transition to modern economic growth that some countries have experienced. In particular, we 
determine the size of the difference in efficiency required to delay the start of the transition to modern economic growth by a certain number of years.

For the purpose at hand, it is important to provide a more thorough picture of the different starting dates for the transition corresponding to the experiences of individual countries. An issue is how to date the start of modern economic growth. Our definition of the start of modern economic growth is the earliest point in a country's history with the property that the trend growth rate is 1 percent or more for all subsequent time. ${ }^{22}$ Figure 7 shows the path of output in a number of countries relative to the industrial leader going back to 1800 . As can be seen, starting dates vary substantially across countries. Mexico started its transition to modern economic growth sometime between 1800 and 1850; Japan started sometime between 1850 and 1900. Brazil started in the early twentieth century, and India started its transition sometime between 1950 and 1980. Each country's income gap with the leader increased prior to starting its transition to modern economic growth.

The key expression for determining the delay in the starting date associated with differences in relative efficiencies is equation (2.12), which rewritten in relative efficiencies is

$$
E_{S}^{i} A_{S t}<\left(\frac{r_{M t}}{\theta}\right)^{\theta}\left(\frac{w_{M t}}{1-\theta}\right)^{1-\theta}
$$

A country will not use the modern production function as long as the relation given by (4.1) is satisfied. Once a country's efficiency, $E_{S} A_{S t}$, exceeds the critical level given by the right-hand side of (4.1), which it must, the country begins its transition to modern economic growth. Assuming as we do that relative efficiencies associated with the traditional production function do not differ across countries, the rental prices of land and labor will not differ much across

\footnotetext{
${ }^{22}$ The concept of trend employed here is a highly smoothed path of per capita income.
} 
countries over the periods when each country specializes in the traditional production function. ${ }^{23}$ Consequently, this critical level of efficiency will not differ much across countries. It follows that the difference in starting dates between two countries $i$ and $j$, with different relative efficiencies, is approximately given by the periods $t_{i}$ and $t_{j}$ for which

$$
E_{S}^{i} A_{S t_{i}}=\left(\frac{r_{M}}{\theta}\right)^{\theta}\left(\frac{w_{M}}{1-\theta}\right)^{1-\theta}=E_{S}^{j} A_{S t_{j}} .
$$

It is not obvious looking at equation (4.2), but the required relative efficiency $E_{S}^{i} / E_{S}^{j}$ that gives rise to a particular delay in the start of the transition depends on the size of the capital share in the modern production function. The reason for this is that the required factor difference in relative efficiencies equals the factor difference in the stock of pure knowledge, $A_{s}$, between starting dates. It follows that the required relative efficiency difference is smaller for larger increases in the stock of pure knowledge between starting dates. The size of the increase in the stock of pure knowledge depends importantly on its asymptotic growth rate, $\gamma_{S}$. The value of this parameter is calibrated so that the growth rate of per capita output associated with the constant growth path of the modern-growth-only model, given by $\left(1+\gamma_{S}\right)^{1 /(1-\theta)}$, equals 2 percent per year. Thus, the calibrated value of $\gamma_{S}$, and hence the implied size of the factor increase in pure knowledge between starting dates $t_{j}$ and $t_{i}$, depends on capital's share in the modern growth production function.

We now compute the efficiency of the early starter relative to a late starter required to generate a given delay in the transition to modern economic growth. We do this for a range of values for the capital share parameter, since the value of capital's share is not well restricted. For

\footnotetext{
${ }^{23}$ They are roughly equal because the rental prices will not be constant in all periods that the economy specializes in the traditional production function. This is because agents will start to accumulate more capital per household member in anticipation of the modern production function being used.
} 
each capital share value, we recalibrate the asymptotic growth rate of pure knowledge, $\gamma_{\mathrm{S}}$, and the value of $A_{s 0}$ so that the country with $E_{s}=1$ always starts its transition in 1700 . These are the only parameters whose values are changed in the experiments.

We assume that late starters are endowed with an initial capital stock equal to the steadystate level associated with the classical model of subsection 2A. For the purpose of determining the date at which an economy starts to use the modern growth function, it is not necessary that we fully specify the population growth function of the late starters. In particular, it is not necessary to specify the population growth function for consumption levels sufficiently greater than the constant consumption level, $c_{m}$, associated with the pre-1700 period. For consumption levels below this, we use a population growth function with a sufficiently large and positive slope at $c_{M}$ and for which $g\left(c_{M}\right)=\left(1+\gamma_{M}\right)^{1 /(1-\phi-\mu)}$. These assumptions ensure that the living standard in a late starter is roughly constant prior to the period it begins its transition.

Table 2 reports the efficiency of the early starter relative to the late starter required to generate a 100-year, a 200-year, and a 250-year delay in the transition to modern economic growth. These delays roughly represent the difference in the start of the transition to modern economic growth between England and Mexico, England and Japan, and England and India. As Table 2 shows, the factor difference in efficiency needed for a given delay decreases as the capital share in the modern production function increases. The size of the required difference needed to delay the start of development for 250 years is plausible for all values of $\theta$ in Table 2 , with $\theta=0.40$ probably at the lower bound of plausible values. 
Table 2. Required Factor Difference in Relative Efficiencies for Delays

\begin{tabular}{|c|c|c|c|}
\hline$\theta$ & 1800 Start & 1900 Start & 1950 Start \\
\hline .40 & 1.60 & 3.2 & 5.7 \\
\hline .50 & 1.25 & 2.5 & 4.0 \\
\hline .60 & 1.20 & 2.2 & 3.3 \\
\hline .70 & 1.18 & 1.9 & 2.5 \\
\hline
\end{tabular}

No Catch-Up After the Transition in Many Countries

A number of countries, many of which are located in Latin America, began modern economic growth toward the end of the nineteenth century. By and large, these countries have failed to eliminate the gap with the leader over the twentieth century. We now examine whether the model can account for this feature of the data. In particular, we seek to determine if the model predicts a narrowing of the gap between a country's income level and the level of the leader once that country begins the transition to modern economic growth.

We address this question by examining whether the model absent any subsequent changes in relative efficiencies predicts a narrowing or widening of the gap between income levels between early and late starters. In particular, we compute the equilibrium paths of per capita output over the 1700 to 2050 period for the model economies associated with the required differences in relative efficiencies listed in Table 2. We also report their asymptotic incomes levels relative to the leader.

Before undertaking these experiments, it is necessary to address two issues. First, it is necessary to specify the population growth rate function for the late starters in these experiments because increases in population affect the size of the increases in per capita output over the 
transition. For this specification, we simply use the post-1800 population growth rates of Mexico for the model economy that starts its transition in 1800, the post-1900 population growth rates of Japan for the model economy that starts its transition in 1900, and the post-1950 population growth rates of India for the model economy that starts its transition in 1950. These population growth data are taken from Lucas (2002, Table 5.1). Second, for capital share values that reflect a broad concept of capital, it is necessary to adjust output by the amount of investment in intangible capital. This adjustment must be made in order to compare the predictions of the model with the national income and product accounts, because the latter fail to measure investments in intangible capital. Thus, GDP in the national accounts corresponds to $Y-X_{I}$ in the model economy.

A country's unmeasured investment as a fraction of its measured output can be determined given the decomposition of the capital share between its physical capital and intangible capital components. For a given total capital share, the physical capital component can be calibrated to the ratio of investment in physical capital to measured GDP in the leader countries of roughly 20 percent. In particular, the individual share parameter values can be calibrated to the steady state of the modern growth-only economy using this observation from the leader countries.

With values of the individual share parameters in the modern growth production function in hand, it is possible to compute the amount of unmeasured investment in any period along an economy's equilibrium path. Table 3 reports the size of the intangible capital share parameter and the asymptotic ratio of intangible capital investment to GDP for each of the total capital share values considered in Table 2. As the total capital share increases, both the intangible 
capital share and the intangible capital investment share of GDP increase. The sizes of the unmeasured investment shares range from 0.0 for $\theta=0.40$ to 0.62 for $\theta=0.70$.

Table 3. Implied Intangible Capital Share and Investments

\begin{tabular}{|c|c|c|}
\hline$\theta$ & $\theta_{I}$ & $X_{I} /\left(Y-X_{I}\right)$ \\
\hline .40 & .00 & .00 \\
\hline .50 & .28 & .26 \\
\hline .60 & .41 & .41 \\
\hline .70 & .53 & .62 \\
\hline
\end{tabular}

Figure 8 plots the path of per capita GDP for late starters relative to the leader over the 1700 to 2050 period. The paths correspond to the case where $\theta=0.40$. The paths are essentially the same for the other capital share values. For reasons of space, they are omitted in this essay. Asymptotically, the model is just the steady state of the modern growth model of subsection $2 \mathrm{~B}$, and so income differences are just $\left(E_{s}^{i} / E_{s}^{j}\right)^{1 /(1-\theta)}$. For the 1800 starter, the asymptotic relative income level is 50 percent of the leader, for the 1900 starter, it is 16 percent, and for the 1950 starter it is 6 percent.

Most of the difference in relative incomes in 2000 is the consequence of the poor country starting the development process later. However, even after starting to develop, a late starter's disparity with the leader increases, although at a much slower rate than before. There are two reasons for this. First, the disparity continues to increase because the traditional production function is still widely used at the start of the transition and the growth rate of TFP associated with the traditional production function is lower than the growth rate of TFP associated with the modern production function. Second, the population growth in these countries tends to be higher compared to the leader over the comparable period. The disparity with the leader stops 
increasing only after the modern production function starts being used on a large scale. For the 1800 starter, the disparity stops increasing around 1900 . For the 1900 starter, the disparity stops increasing around 2000. And for the 1950 starter, the disparity stops increasing around $2050{ }^{24}$ The increase in disparity over the $1950-2000$ period for the 1950 starter is consistent with the fact that many sub-Saharan countries have fallen further behind the leader in the 1950-2000 period despite experiencing absolute increases in living standards over this period.

Laggards do experience larger increases in their income over their transition periods compared to earlier starters. For example, the country that starts its transition in 1700 realizes a factor increase of 1.2 in its per capita income by 1750 . In comparison, the country that starts its transition in 1900 realizes a factor increase of 2 in its per capita income over the next 50 years. ${ }^{25}$ The reason for this difference is that the growth rate of knowledge associated with the modern production function is initially low, but rises over time. Thus, TFP growth in the modern production function over a late starter's transition period is higher than an earlier starter's transition period. This gives late starters an inherent advantage.

The data needed to verify whether this pattern exists are not readily available because per capita income estimates going back to the eighteenth century exist for only a limited number of countries. Thus, it is not possible to say whether transition periods have become shorter over time. There is, however, strong evidence that late starters have been able to double their incomes in far shorter time periods than earlier starters.

Figure 9 documents this general pattern. It plots the number of years a country took to go from 10 percent to 20 percent of the 1985 U.S. per capita income level versus the first year that

\footnotetext{
${ }^{24}$ This is a key difference between our formulation and that of Ngai (forthcoming). Ngai examines the effect of policy on the starting date within Hansen and Prescott's overlapping generations model. In contrast, she finds that some part of the income gap will be eliminated once poor countries start their transitions.

${ }^{25}$ This assumes the same population growth functions for both economies.
} 
country achieved the 10 percent level. The 1985 U.S. level was 20,000 in 1990 dollars. The set of countries considered had at least 1 million people in 1970 and had achieved and sustained per capita income of at least 10 percent of the 1985 U.S. level by 1965 . There are 56 countries that fit these criteria and for which data are available. Of these 56 countries, all but four managed to double their per capita income by 1992. The four exceptions all had protracted armed insurgencies that disrupted their development.

The difference in the length of the doubling period between the sets of late and early starters is dramatic. For early starters, which are those achieving 10 percent of the 1985 U.S. level before 1950, the median length of the doubling period is 45 years. For late starters, defined as those achieving 10 percent of the 1985 U.S. level after 1950, the median length of the doubling period is 15 years. The choice of starting level is not important. A similar pattern emerges when the starting level is fixed at 5 percent and at 20 percent of the 1985 U.S. level.

Although the model absent changes in relative efficiency infers an advantage to late starters, quantitatively it is inconsistent with the number of years in which many late starters have been able to double their income. Many late starters that doubled their income in less than a 35-year period after 1950 did in fact narrow the gap with the leader over that period. The unified theory absent changes in relative efficiencies does not predict any catch-up for late starters. For the theory to account for this catch-up, it must consider changes in relative efficiency in a given country over time.

\section{Catch-Up and Growth Miracles}

We now examine whether the theory can account for the record of catch-up. A key feature of the evolution of international income levels is that many countries have been able to narrow the gap with the leaders, with some realizing large increases in output relative to the 
leader in a relatively short period of time. A number of countries, primarily located in Western Europe, caught up to the leader in the post-World War II period. A number of other countries primarily located in Southeast Asia eliminated a large fraction of their gap with the leader in this period. Some of these countries had miraculous growth experiences doubling their living standards in less than a decade in the post-1950 period. These growth miracles are a relatively recent phenomenon and are limited to countries that were relatively poor prior to undergoing their miracle. No country at the top of the income distribution has increased its per capita income by a factor of 4 in 25 years, and the leader has always taken at least 80 years to quadruple its income.

To account for the catch-up, including growth miracles, the theory requires an increase in the efficiency of a country relative to the leader. ${ }^{26}$ In light of the Parente and Prescott (2000) theory, these changes in relative efficiency are easy to understand. Namely, they reflect policy changes. Following an improvement in policy that leads to a significant and persistent increase in efficiency, the theory predicts that the income of a late starter will go from its currently low level relative to the leader to a much higher level. As it does, its growth rate will exceed the rate of modern growth experienced by the leader countries, and the gap between its income and the leader's income will be narrowed.

We now consider an increase in a late starter's relative efficiency. In particular, we examine whether the unified theory can account for the growth miracle of Japan. Figure 10 depicts the path of per capita output for the Japanese and U.S. economies over the 1900 to 1995 period. There is really nothing special about Japan relative to other economies that similarly experienced growth miracles. It would have been just as easy to study the cases of other growth

\footnotetext{
${ }^{26}$ Additionally, an increase in efficiency can hasten the start of the transition to modern growth for countries that have not already begun this phase of development.
} 
miracle countries such as China, South Korea, and Taiwan in this experiment. The precise time period of the Japanese growth miracle we consider in the analysis is the 1957-69 period. We choose this period because by 1957 Japan had fully recovered from the wartime disruptions. Moreover, this period is one of the most dramatic in terms of Japan's catch-up. In this 12-year period, per capita GDP doubled from 25 percent of the leader to 50 percent of the leader (Summers and Heston, 1991). This catching-up was not the result of the leader's growth rate slowing down. Indeed, U.S. per capita GDP grew by 40 percent in this period. The Japanese economy in this period is a dramatic example of catching up.

The experiment assumes an unexpected increase in 1957 in the relative efficiency of the model economy, which started its transition in 1900, to the level of the leader. This assumption is made because the data suggest that Japan in the 1957-69 period was converging to the U.S. balanced growth path. In calculating the equilibrium path of the model economy following this increase, we take the initial population to be the population corresponding to the equilibrium path of the model economy that starts the transition in 1900. The initial capital stock is assumed to be such that per capita GDP relative to the leader equals 25 percent. ${ }^{27}$ The population growth rate function for the model economy is the same as before and is based on Japanese population dynamics.

The important finding is that the total capital share must be large for an economy to take 12 years to move from 25 percent to 50 percent of the leader. Figure 11 plots the path of per capita GDP predicted by the model economy over this period for various values of $\theta$. For a value

\footnotetext{
${ }^{27}$ In the case where capital is broadly defined, we assume the initial mix of physical and intangible capital is optimal in the sense that returns would be equal.
} 
of $\theta$ equal to 0.40 , the predicted path shows too large an increase over the period. At the other end of the range, namely, $\theta=0.70$, the predicted path shows too small an increase over this time period. This leads us to conclude that capital share values in the range from 0.55 to 0.65 are consistent with the growth miracles. ${ }^{28}$

It is possible to introduce this increase in efficiency in the poor country at a much earlier date, say, in 1800 . The theory does not, however, predict that the poor country will experience a growth miracle. The theory, therefore, is consistent with the fact that growth miracles are a relatively recent phenomenon. Growth miracles are a relatively recent phenomenon because, as Figure 8 shows, differences in relative incomes between the low-efficiency and high-efficiency countries widen over time before leveling off. This widening is due to growth in the stock of pure knowledge associated with the modern production function, which the high-efficiency country uses from a very early date. Thus, as one goes back in time, the gap that a low-efficiency country could close by becoming a high-efficiency country becomes smaller and smaller. Obviously, if the gap is less than 50 percent, the low-efficiency country could never double its income in less than a decade. For the same reason, the unified theory is consistent with the fact that late starters have been able to double their incomes in far shorter times compared to early starters.

The theory is also consistent with the fact that growth miracles are limited to countries that were initially poor at the time their miracles began. Growth miracles are limited to this set of countries because a growth miracle in the theory requires a large increase in a country's relative efficiency. A large increase in efficiency can only occur in a poor country with a currently low

\footnotetext{
${ }^{28}$ There are a number of reasons capital's share may be somewhat less than 0.60 . For one, we abstracted from leisure. For another, we abstracted from household durables. For an in-depth discussion of this issue, see Parente and Prescott (2000).
} 
efficiency parameter. This rules out a rich country, which by definition uses its resources efficiently, from having a growth miracle.

\section{Unmeasured Investment}

For capital share values that are consistent with the evolution of international income levels, the implied size of unmeasured investment is between 35 and 55 percent of GDP. An important question is whether these intangible capital investment share numbers are plausible. This is not an easy question to answer. The difficulty in coming up with measures of the size of intangible capital investment is that the national income and product accounts (NIPA) treat investments in intangible capital as ordinary business expenses. Such investments, therefore, are not measured.

To better understand this, consider the case where a firm hires computer instructors for $\$ 100$ to train its workers to use the latest software. This expenditure of $\$ 100$ by the firm clearly represents an investment in the stock of intangible capital. It is not included in GDP in the national accounts. In terms of the national accounts, the $\$ 100$ is the payment to the instructors, and so enters the income side of the national accounts under compensation to employees. However, since the expenditure is treated as an ordinary business expense, the firm's accounting profits are lowered by $\$ 100$, and corporate profits in the national accounts are lowered by $\$ 100$. These entries exactly offset each other so the transaction has no effect on either the income side or the output side of the national accounts. The investment in intangible capital, thus, goes unmeasured.

Parente and Prescott (2000) attempt to estimate the size of intangible capital investment in the U.S. economy by examining micro evidence of the size of the investments that firms and people make in intangible capital. In constructing their estimates, Parente and Prescott (2000) 
use the principle implied by theory that investment is any allocation of resources that is designed to increase future production possibilities. Using this principle, they identify such activities as starting up a new business, learning-on-the-job, training, education, research and development, and some forms of advertising as investments in intangible capital. ${ }^{29}$ They conclude that the size of this investment may be as large as 50 percent of GDP. Such estimates are consistent with capital share values between one-half and two-thirds.

\section{Catching Up}

The implication of the theory is that countries will be rich if they do not constrain production units as to which technologies can be operated and the manner in which a given technology can be operated. Currently poor countries will catch up to the industrial leaders in terms of production efficiency if existing barriers to efficient production are eliminated and an arrangement is set up to ensure that barriers will not be re-erected in the future. The removal of such constraints is a necessary condition for catching up. As discussed in Section 3, there is strong evidence that suggests that these constraints exist to protect the interests of industry groups vested in the current production process. As such, their removal is likely to be contentious. For this reason, it is instructive to examine the record on catch-up in greater depth for the purpose of determining the circumstances under which barriers to efficient use of technology were reduced and catching up with the efficiency leader occurred.

\section{A. Catch-up Facts}

Catching up is not uniform across regions, as can be seen in Figure 1. Latin American countries began modern economic growth in the late nineteenth century, and this set has not

\footnotetext{
${ }^{29}$ Additionally, McGrattan and Prescott (2002) estimate the size of unmeasured investment in the corporate sector only and conclude that it is roughly 10 percent of GDP.
} 
subsequently closed the living standard gap with the industrial leader; the per capita income of this set remained at roughly 25 percent of the industrial leader throughout the twentieth century. In comparison, Asian countries with the exception of Japan began modern economic growth later. This set of countries experienced significant catch-up in the last half of the twentieth century.

The large Western European countries, namely, Germany, Italy, and France, caught up to the industrial leader in the post-World War II period after trailing the leader for 100 years. Modern economic growth in these countries began about 1840. At that time, their living standard was about 60 percent of the industrial leader, which at that time was the United Kingdom. For nearly 100 years, these countries maintained an income level that was about 60 percent that of the industrial leader. In the post-World War II period, output per hour worked in these countries, which is a good measure of living standards because it recognizes the value of nonmarket time, increased from 38 percent of the U.S. level in 1950 to 73 percent in 1973 and to 94 percent in 1992. Per capita output in Western Europe is still lower than the U.S. level, but this difference is accounted for by differences in the fraction of time that people work in the market, and not in the efficiency with which resources are used.

Another important example of catching up is the U.S. development experience in the 1865-1929 period. In 1870, U.K. per capita GDP was nearly a third higher than that of the United States. By 1929, the United Kingdom's per capita GDP was a third lower than that of the United States. The dramatic growth performance of the United States in this period is an important fact that needs to be explained. 


\section{B. Reasons for Catching Up or Not Catching Up}

\section{The United States}

We begin with the question of why the United States caught up with and surged past the United Kingdom in the $1865-1929$ period. Our answer to this question is that the United Sates was and continues to be a free trade club, while the United Kingdom was not a member of a free trade club in this earlier period. Our definition of a free trade club is as follows. A set of states constitutes a free trade club if it meets two conditions. Member states cannot impose tariffs and other restrictions on the import of goods and services from other member states. In addition, member states must have a considerable degree of economic sovereignty from the collective entity. Just as no single state is able to block the movement of goods between states, the collective entity cannot block the adoption of a superior technology in one of its member states. Thus, a free trade club in our definition is far more than a set of countries with a free trade agreement.

The 50 United States certainly satisfy these two conditions, and thus, are a free trade club. The individual state governments have a considerable degree of sovereign power over the federal government. Additionally, the interstate commerce clause gives the federal government the right to regulate interstate commerce and prevent individual states from imposing tariffs and other restrictions on the import of goods and services. With the formation of the North American Free Trade Agreement and the recent approval of the free trade agreements with Chile and Singapore, the set of states constituting the free trade club to which the United States as a whole belongs may be getting larger. ${ }^{30}$

\footnotetext{
${ }^{30}$ The United States was probably more of a free trade club in the 1865-1929 period compared to the post-1929 period. This is because the interstate commerce clause was interpreted in the earlier period to mean that states could not interfere with interstate commerce. After 1929, the interpretation changed when the meaning of the clause was broadened to allow federal government to regulate interstate commerce.
} 
A free trade club, which prohibits individual states from discriminating against the goods produced in other member states and against producers from other member states operating within their borders, has the advantage that industry insiders in the various member states face elastic demand for what they supply. As a consequence, they are not hurt by the adoption of more efficient production methods as the increase in output leads to an increase in the employment of the factor they supply in that industry. If demand were inelastic, an increase in efficiency would lead to a fall in employment, something that industry insiders would strongly oppose. $^{31}$ Thus, a free trade club provides less incentive for groups of factor suppliers to form insider groups and block the adoption of more efficient technologies.

A free trade club need not be composed of individual democratic states, as is the case with the United States. However, in democratic states with legislatures representing districts, vested interests in other districts have a limited ability to block the adoption of technology in a given district if the citizens of the given district want that technology adopted. In the United States, for example, Toyota was able to locate an automobile plant with its just-in-time production in Kentucky in 1985. Those with vested interests in the less efficient technology in Michigan and other states with a large automotive industry were not able to prevent this from happening. The people in Kentucky wanted the large construction project and the high paying jobs in the automobile factory in their state. In 1995 political pressure mounted to block the import of luxury automobiles from Japan. Toyota responded by building plants in other states, including Indiana and West Virginia in 1998 and Alabama and Texas in 2003. These location decisions were as much politically motivated as economically motivated, and Toyota is close to being the third largest automobile producer in North America.

\footnotetext{
${ }^{31}$ Dowrick and Spencer (1994) review empirical literature that finds union resistance to the adoption of labor-saving innovations occurs within an industry when employment and wages will fall as the result of the adoption of the
} 


\section{Western Europe}

Western Europe caught up to the United States in terms of labor productivity in the 1957-93 period for the same reason. With the creation of the European Union, Western Europe became an equally important free trade club. Its states enjoy even greater sovereignty than do U.S. member states. The German state cannot block the Toyota introduction of just-in-time production in Wales even though German politicians would if they could in response to domestic political pressure. If Toyota starts gaining market share, it will not be long before the auto industry throughout Europe adopts the superior technology, and productivity in the automobile industry increases. This is just competition at work.

The historical statistics lend strong empirical support to the theory that a trading club arrangement results in greater efficiency of production. Table 4 reports labor productivity defined as output per work hour for the original members of what became the European Union and the labor productivity of members that joined in the 1970s and 1980s. Productivities are reported for an extended period before the EU was formed as well as for the period subsequent to its creation.

The Treaty of Rome was signed in 1957 by Belgium, France, Italy, Netherlands, Luxembourg, and West Germany to form the union. In 1973 Denmark, Ireland, and the United Kingdom joined. In 1981 Greece joined, followed by Portugal and Spain in 1986. The most recent additions are Austria, Finland, and Sweden in 1995.

One striking fact is that prior to forming the European Union, the original members had labor productivity that was only half that of the United States. This state of affairs persisted for over 60 years with no catching up. However, in the 36 years after forming what became the EU,

innovation. They go on to establish conditions under which this will and will not occur. 
the Treaty of Rome signers caught up with the United States in terms of labor productivity. The factor leading to this catch-up is an increase in the efficiency with which resources are used in production. Changes in capital/output ratios are of little significance in accounting for the change in labor productivity. ${ }^{32}$ Productivity of the EU countries that joined in 1973 has also been catching up to the U.S. level since these countries joined the EU. It will be interesting to see if Greece and Portugal, the two EU countries that have significantly lower productivity than the other EU members, continue to improve their relative productivity performance.

Another interesting comparison is between the productivity performance of the set of original EU members and the set of Western European countries that either joined in 1995 or still have not joined the EU. This latter set consists of Switzerland, Austria, Finland, and Sweden. ${ }^{33}$ We label this set of four countries the others. Table 5 reports labor productivities of the others to the original EU countries.

The important finding is that the original EU countries and the others are equally productive in the pre-World War II period. In the 36 years from 1957 to 1993, the others fell from 1.06 times as productive as the original EU countries to only 0.81 times as productive in 1993. This constitutes strong empirical evidence that membership in the EU fosters higher productivity.

The EU is scheduled to expand from 15 to 25 members in March of 2004. The new countries include the Czech Republic, Hungary, Poland, and the Slovak Republic, which are all former Communist states located in central Europe. Maddison (2001, p. 337) estimates that their

\footnotetext{
${ }^{32}$ See Prescott (2002).

${ }^{33}$ Norway is not included in this set of countries because of the large size of its oil industry.
} 
per employee GDP, which is a good proxy for productivity, was about 40 percent of Western Europe in 1998. If history is any guide, these countries will narrow the productivity gap with the original EU members and the United States. Three of the ten scheduled joiners, namely, Cyprus, Malta and Slovenia, already have relatively high GDP per capita and have little catching up to do. They are all small countries that are highly economically integrated with Western European states and have been de facto members of the Western European trading club for a number of years. Countries that are economically integrated with other sovereign states can be rich, even if no formal treaty exists. 
Table 4. Labor Productivities of European Union Members as a Percentage of U.S. Productivity

\begin{tabular}{|c|c|c|}
\hline Year & Original Members & Members Joining in 1973 \\
\hline 1870 & 62 & \\
\hline 1913 & 53 & \\
\hline 1929 & 52 & 57 \\
\hline 1938 & 53 & 66 \\
\hline 1957 & 78 & 76 \\
\hline 1973 & 94 & 83 \\
\hline 1983 & 102 & 85 \\
\hline 1993 & 101 & \\
\hline 2002 & & \\
\hline
\end{tabular}

a The prewar numbers are population weighted labor productivity numbers from Maddison (1995). The postwar numbers are also population weighted and were obtained from Maddison's Web page, http://www.eco.rug.nl/GGDC/index-series.html\#top. 


\section{Table 5. Labor Productivity of Other Western European Countries as a Percentage of Original EU Members ${ }^{a}$}

\begin{tabular}{lc}
\hline Year & Others/Original \\
1900 & 103 \\
1913 & 99 \\
1938 & 103 \\
1957 & 106 \\
1973 & 96 \\
1983 & 85 \\
1993 & 81
\end{tabular}

${ }^{a}$ The prewar figures are from Maddison (1995). For this period, GDP per capita is used as a proxy for productivity. The postwar numbers are also population weighted and were obtain from Maddison's Web page, http://www.eco.rug.nl/GGDC/index-series.html\#top.

\section{Latin America}

Latin American countries failed to catch up because they have failed to develop into a free trade club. For this reason, Latin American per capita income has remained at the same level relative to the leader for the last century. There is no free movement of goods and people between the set of relatively sovereign states. A consequence of this is that often industry insiders in the sovereign states face inelastic demand for their products or services, and this leads them to block the adoption of more efficient production practices. If Latin American countries were to decentralize and restrict the authority of their central governments to be like the United States in the 1865-1929 period, then they too would quickly become as rich as Western Europe and the United States, or maybe richer. 


\section{Southeast Asia}

The reasons for catch-up in Asia are slightly more involved. Countries such as South Korea, Taiwan, and Japan were forced to adopt policies that did not block efficient production as a condition for support from the United States. Further, the need to finance national defense made protecting those with vested interests in inefficient production too expensive to South Korea and Taiwan. These development miracles along with the Hong Kong and Singapore growth miracles made it clear to the people of the democratic states in the region that the policy that their elected representatives followed mattered for their living standard. Their elected representatives had no choice but to cut back on protecting industry insiders with vested interests in inefficient production or be voted out of office.

\section{China}

The recent catching up done by China is primarily a result of it becoming a free trade club. The rapid development of China began in 1978 when the Chinese government became more decentralized, with much of the centralized planning system dismantled. Although the central government gave more power to regional governments, it did not give the regional governments the right to restrict the flow of goods across regions. In fact, when individual regions attempted to erect trade barriers in the late 1980s and early 1990s, the central government immediately took steps to restore the free flow of goods and services. ${ }^{34}$ The resulting competition between businesses in various provinces led to rapid growth in living standards.

\footnotetext{
${ }^{34}$ See Young (2000).
} 
Russia

While China's performance since its transition to capitalism has been spectacular, the same cannot be said for Russia's performance since its transition to capitalism. Whereas China has closed some of its income gap with the leader, Russia has fallen further behind the leader. Between 1985 and 1998, Russia's per capita GDP fell from 30 percent to 22 percent of the U.S. level (Heston, Summers, and Aten, 2002, p. 62). Why has Russia failed to catch up to the leader following its switch to capitalism?

Russia is not a free trade club and does not belong to a free trade club. It is not economically integrated with Western Europe. It is large enough both in terms of population and land that its regions could make up a free trade club. However, this is not the case. Local and regional governments in Russia have the power to discriminate against producers from other member states operating within their borders and to restrict the flow of goods and people into and out of their region. For example, in response to the financial crisis of August 1988, regional governments prohibited exports of food goods from their regions and put in place price ceilings for many of those items. Regional governments further have the discretion to use federal funds for purposes they see fit. Often, these funds are used to keep inefficient industries afloat. Local governments also have control over the use and privatization of land. There are essentially no land and real estate markets. In general, the purchase of land and the conversion of nonindustrial structures for new commercial activity are not possible. During the privatization phase, local governments refused to lease any property that had not been used commercially. $^{35}$

\footnotetext{
${ }^{35}$ Parente and Riós-Rull (2001) document the greater prevalence of specialized groups of factor suppliers in Russia compared to China, and the successful efforts by local governments in Russia to prevent the adoption of better technologies.
} 


\section{Concluding Remarks}

Will the whole world be rich by the end of the twenty-first century? The implication of the theory reviewed in this essay is that a country will catch up to the leading industrial countries only if it eliminates the constraints relating to the use of technology. Although it is clear what a country must do to become rich, it is not clear whether a country will have either the political will or political power to make the necessary reforms. Removal of the constraints to the efficient use of resources is bound to be contentious, because such constraints typically exist to protect specialized groups of factor suppliers and corporate interests. As recent events in Argentina show, these groups can topple a government.

The historical record of catch-up suggests that joining a free trade club is an important way by which a society can eliminate barriers that were erected to protect specialized groups of factor suppliers and corporate interests and reduce the likelihood that such groups will seek similar protection in the future. The expansion of the European Union as well as the recent U.S. free trade agreements with Central American countries, Chile, Singapore, and Australia are encouraging events. These events show that more and more regions are gaining the political will to reduce these constraints. However, many other regions of the world, particularly Africa, the Indian subcontinent, and South America, still lack this will.

Why one country has this will and another does not is an important open question. As a first step toward answering it, it is imperative that economists better understand how it is that constraints to the efficient use of resources come to be imposed on a society in the first place. Some progress is being made in this area. Grossman and Helpman (1994), Holmes and Schmitz (1995; 2001), Krusell and Ríos-Rull (1996; 2002), McDermott (1999), Kocherlakota (2000), Bridgman, Livshits, and MacGee (2001), Parente and Ríos-Rull (2001), Samaniego (2001), 
Teixeira (2001), and Parente and Zhao (2003) all deal with this issue to some degree. In our view, this will continue to be an important research area in the years to come. 


\section{References}

Bairoch, P. Economics and World History: Myths and Paradoxes (Chicago: University of Chicago Press, 1993).

Becker, G. S. “An Economic Analysis of Fertility.” In Richard Easterlin, ed., Demographic and Economic Change in Developed Countries. Universities-National Bureau Conference Series, no. 11 (Princeton, N.J.: Princeton University Press, pp. 209-40, 1960).

Becker, G. S., K. M. Murphy, and R. Tamura. "Human Capital, Fertility, and Economic Growth.” Journal of Political Economy 98 (1990), S12-37.

Bridgman, B., I. Livshits, and J. MacGee. "For Sale: Barriers to Riches." Unpublished Manuscript, Federal Reserve Bank of Minneapolis, 2001.

Clark, G. "Nominal and Real Male Agricultural Wages in England, 1250-1850." Unpublished Manuscript, University of California, Davis, 1998.

Djankov, S., R. La Porta, F. Lopez-de-Silanes, and A. Shleifer. "The Regulation of Entry." Quarterly Journal of Economics 117 (2002), 1-37.

Doepke, M. Fertility, Income Distribution, and Growth. Doctoral Dissertation, University of Chicago, 2000.

Dowrick, S. and B. J. Spencer. "Union Attitudes to Labour-Saving Innovation: When Are Unions Luddites?" Journal of Labor Economics 12 (1994), 316-44.

Galor, O. and D. N. Weil. "Population, Technology, and Growth: From Malthusian Stagnation to the Demographic Transition and Beyond.” American Economic Review 90: (2000), 80628.

Gollin, D. “Getting Income Shares Right.” Journal of Political Economy 110 (2002), 458-74. 
Grossman, G. M., and E. Helpman. "Protection for Sale.” American Economic Review 84 (1994), 833-50.

Hall, R. E., and C. I. Jones. "Why Do Some Countries Produce So Much More Output Per Worker than Others?" Quarterly Journal of Economics 114 (1999), 83-116.

Hansen, G. D., and E. C. Prescott. "Malthus to Solow." American Economic Review 92 (2002), $1205-17$.

Hendricks, L. "How Important Is Human Capital for Development? Evidence from Immigrant Earnings.” American Economic Review 92 (2002), 198-219.

Hendricks, L. "Taxation and the Intergenerational Transmission of Human Capital." Journal of Economic Dynamics and Control 27 (2003), 163-62.

Herrendorf, B., and A. Teixeira. "Monopoly Rights Can Reduce Income Big Time.” University of Carlos III working paper, July 2003.

Heston, A., R. Summers, and B. Aten, Penn World Table Version 6.1, Center for International Comparisons at the University of Pennsylvania (CICUP), October 2002.

Hoffman, P. T. Growth in a Traditional Society: The French Countryside, 1450-1815 (Princeton, NJ: Princeton University Press, 1996).

Holmes, T. J., and J. A. Schmitz, Jr. "Resistance to New Technology and Trade Between Areas." Federal Reserve Bank of Minneapolis Quarterly Review 19 (Winter 1995), 2-17.

Holmes, T. J., and J. A. Schmitz, Jr. "A Gain from Trade: From Unproductive to Productive Entrepreneurship.” Journal of Monetary Economics 47 (2001), 417-46.

Hornstein, A. and E. C. Prescott. "The Firm and the Plant in General Equilibrium Theory." In R. Becker, M. Boldrin, R. Jones, and W. Thomson, eds., General Equilibrium, Growth, 
and Trade. Vol. 2. The Legacy of Lionel McKenzie (San Diego: Academic Press, pp. 393-410, 1993).

Johnson, D. G. "Population, Food, and Knowledge." American Economic Review 90 (2000), 114.

Klenow, P. J., and A. Rodriguez-Clare. "Economic Growth: A Review Essay." Journal of Monetary Economics 40 (1997), 597-617.

Kocherlakota, N. R. "Building Blocks for Barriers to Riches." Unpublished Manuscript, Federal Reserve Bank of Minneapolis, 2000.

Krusell P., and J.-V. Ríos-Rull. "Vested Interests in a Positive Theory of Stagnation and Growth.” Review of Economic Studies 63 (1996), 301-29.

Krusell, P., and J.-V. Ríos-Rull. "Politico-economic Transition." Review of Economic Design 7 (2002), 309-29.

Kuznets, S. Modern Economic Growth (New Haven, Conn.: Yale University Press, 1966).

Lucas, R. E., Jr. Lectures on Economic Growth (Cambridge: Harvard University Press, 2002).

Maddison, A. Dynamic Forces in Capitalist Development: A Long-Run Comparative View (Oxford University Press, 1991).

Maddison, A. Monitoring the World Economy: 1820-1992 (Paris: Organisation for Economic Co-operation and Development, 1995).

Maddison, A. The World Economy: A Millenium Perspective (Paris: Organisation for Economic Co-operation and Development, 2001).

Malthus, T. R. "First Essays on Population" [1797]. Reprints of Economic Classics (New York: Augustus Kelley, 1965). 
McDermott, J. "Mercantilism and Modern Growth.” Journal of Economic Growth 4 (1999), 5580.

McGrattan, E. R., and E. C. Prescott. "Taxes, Regulations, and the Value of U.S. Corporations: A General Equilibrium Analysis." Staff Report 309, Federal Reserve Bank of Minneapolis, August 2002.

Mokyr, J. The Lever of Riches: Technological Creativity and Economic Progress (New York: Oxford University Press, 1990).

Ngai, L. R. "Barriers and the Transition to Modern Economic Growth." Journal of Monetary Economics, forthcoming.

Parente, S. L., and E. C. Prescott. "Monopoly Rights: A Barrier to Riches," American Economic Review 89 (1999), 1216-33.

Parente, S. L., and E. C. Prescott. Barriers to Riches (Cambridge: MIT Press, 2000).

Parente, S. L., and J.-V. Ríos-Rull. "The Success and Failure of Economic Reforms in Transition Economies.” Unpublished Manuscript, University of Illinois, 2001.

Parente, S. L., and R. Zhao. "Path Dependence, Uneven Industrialization, and Special Interests." Unpublished Manuscript, University of Illinois, 2003.

Prescott, E. C. "Prosperity and Depression," American Economic Review 92(2), (2002), 1-15.

Ricardo, D. "On the Principals of Political Economy and Taxation" [1817]. In Pier Sraffa, ed., The Works and Correspondences of David Ricardo, Vol. 1 (Cambridge: Cambridge University Press, 1951).

Samaniego, R. M. “Does Employment Protection Inhibit Technology Diffusion?” Unpublished Manuscript, University of Pennsylvania, 2001. 
Schmitz, J. A., Jr. "Government Production of Investment Goods and Aggregate Labor Productivity." Journal of Monetary Economics 47 (2001), 163-87.

Solow, R. M. Growth Theory: An Exposition (New York: Oxford University Press, 1970).

Summers, R. and A. Heston. "The Penn World Table (Mark 5): An Expanded Set of International Comparisons, 1950-1988." Quarterly Journal of Economics 106 (1991), $327-68$.

Tamura, R. F. "Fertility, Human Capital, and the "Wealth of Nations."” Doctoral Dissertation, University of Chicago, 1988.

Teixeira, A. "Effects of Trade Policy on Technology Adoption and Investment." Unpublished Manuscript, 2001.

Young, A. “The Razor's Edge: Distortions and Incremental Reform in the People's Republic of China." Quarterly Journal of Economics 115 (2000), 1091-1135. 
Figure 1: Evolution of International Incomes: 1700-1990 (Fraction of Leader)

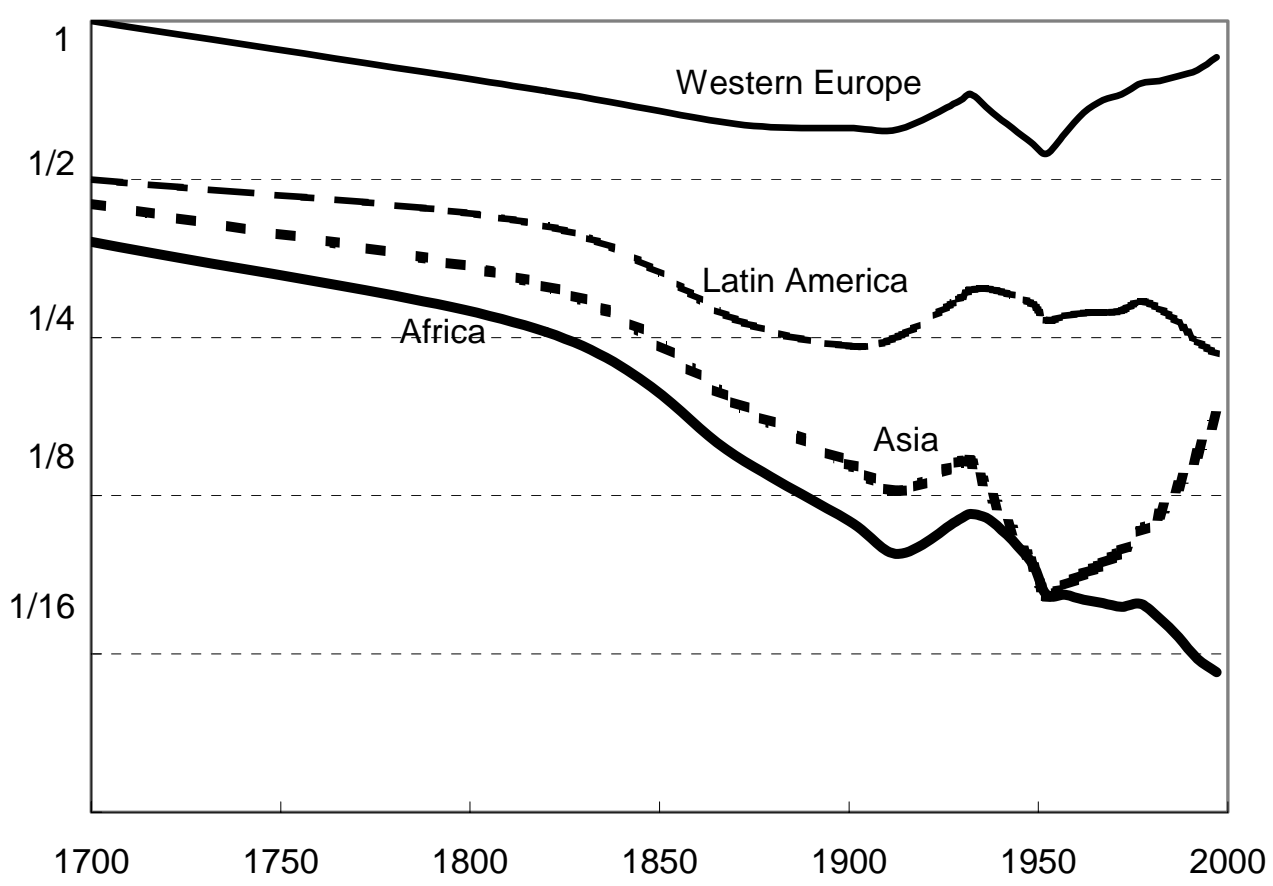

Source: Maddison (1995)

Figure 2: Income per Capita of the Leader Relative to the Pre-1800 Level

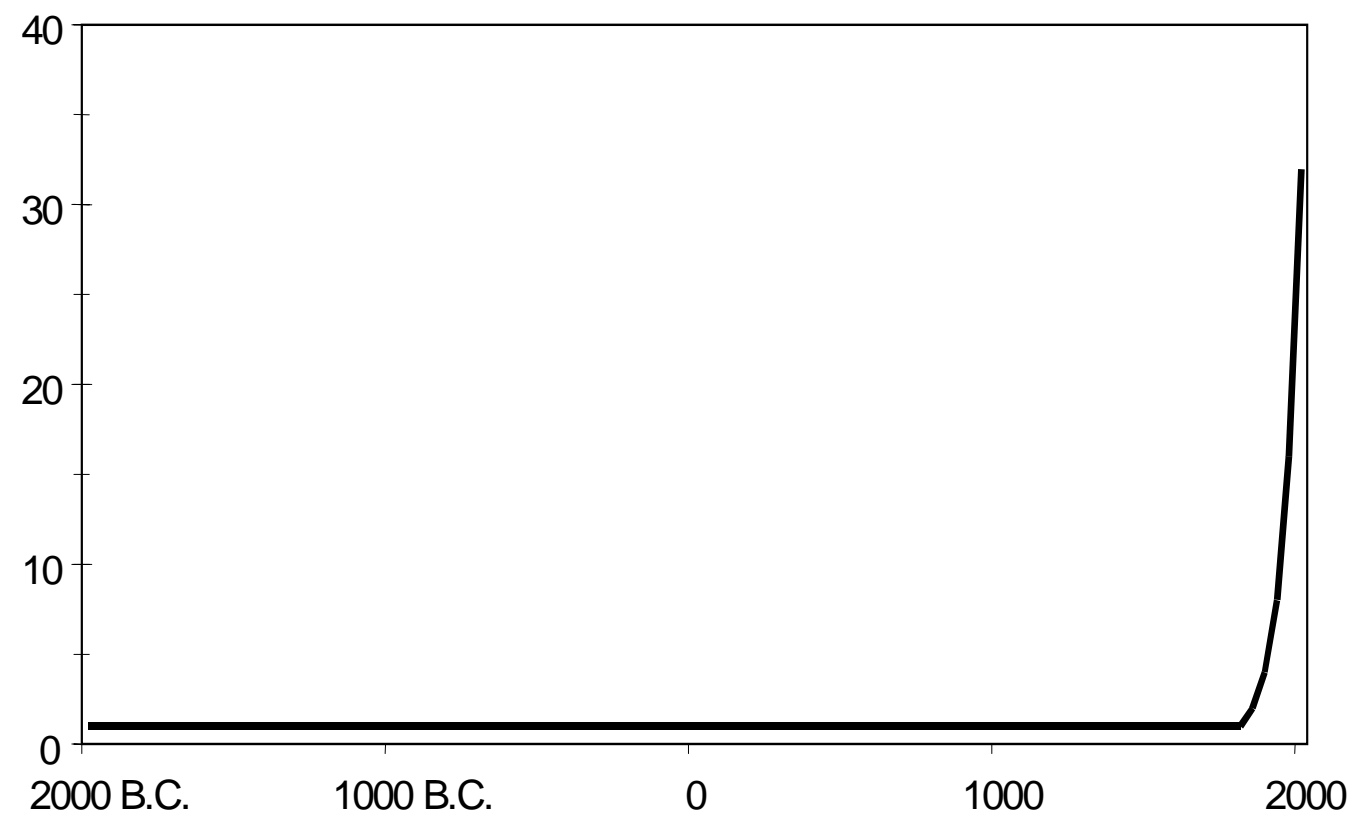

Source: Bairoch (1993) 
Figure 3: Population Growth Function $g(c)$ Implied by U.K. Data

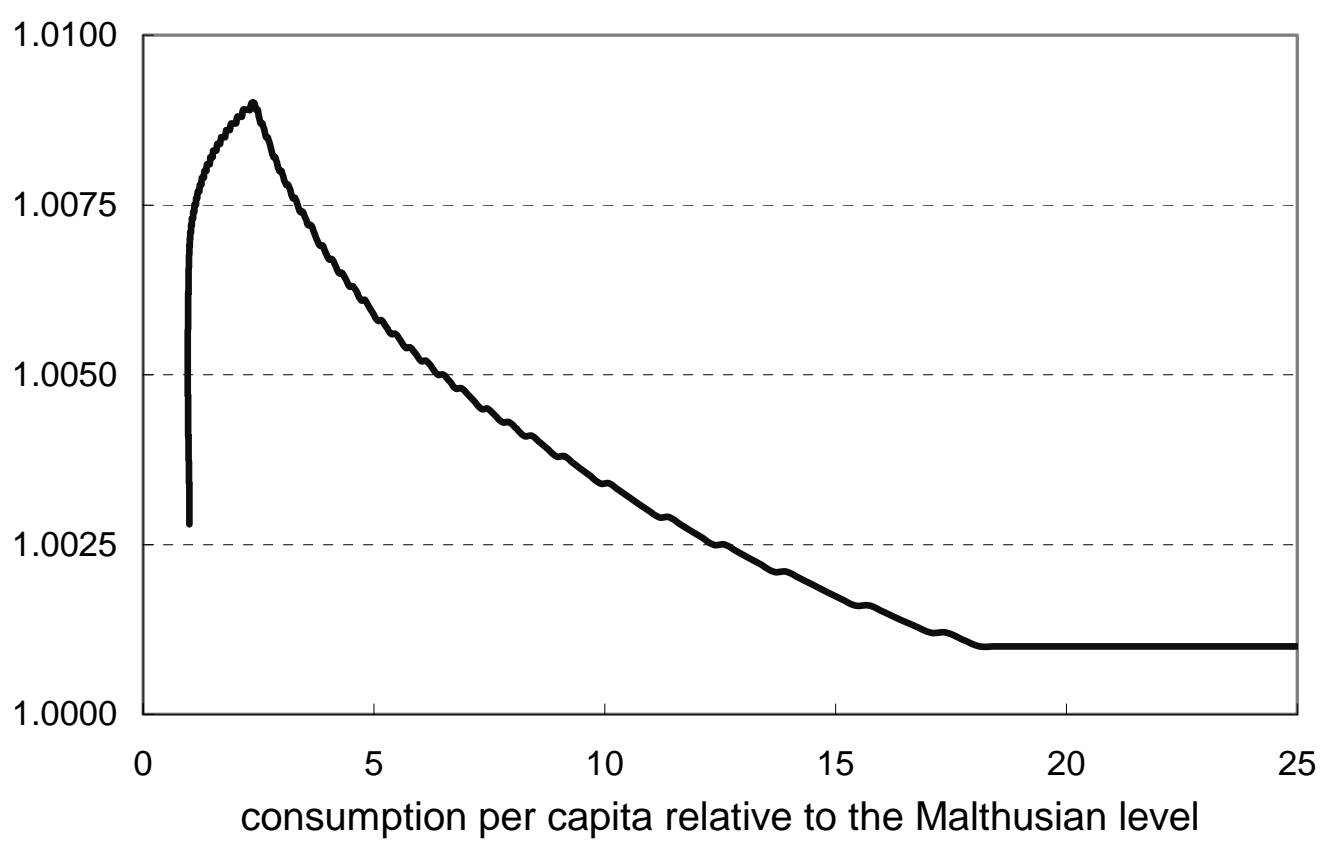

Figure 4: Income per Capita Relative to 1700

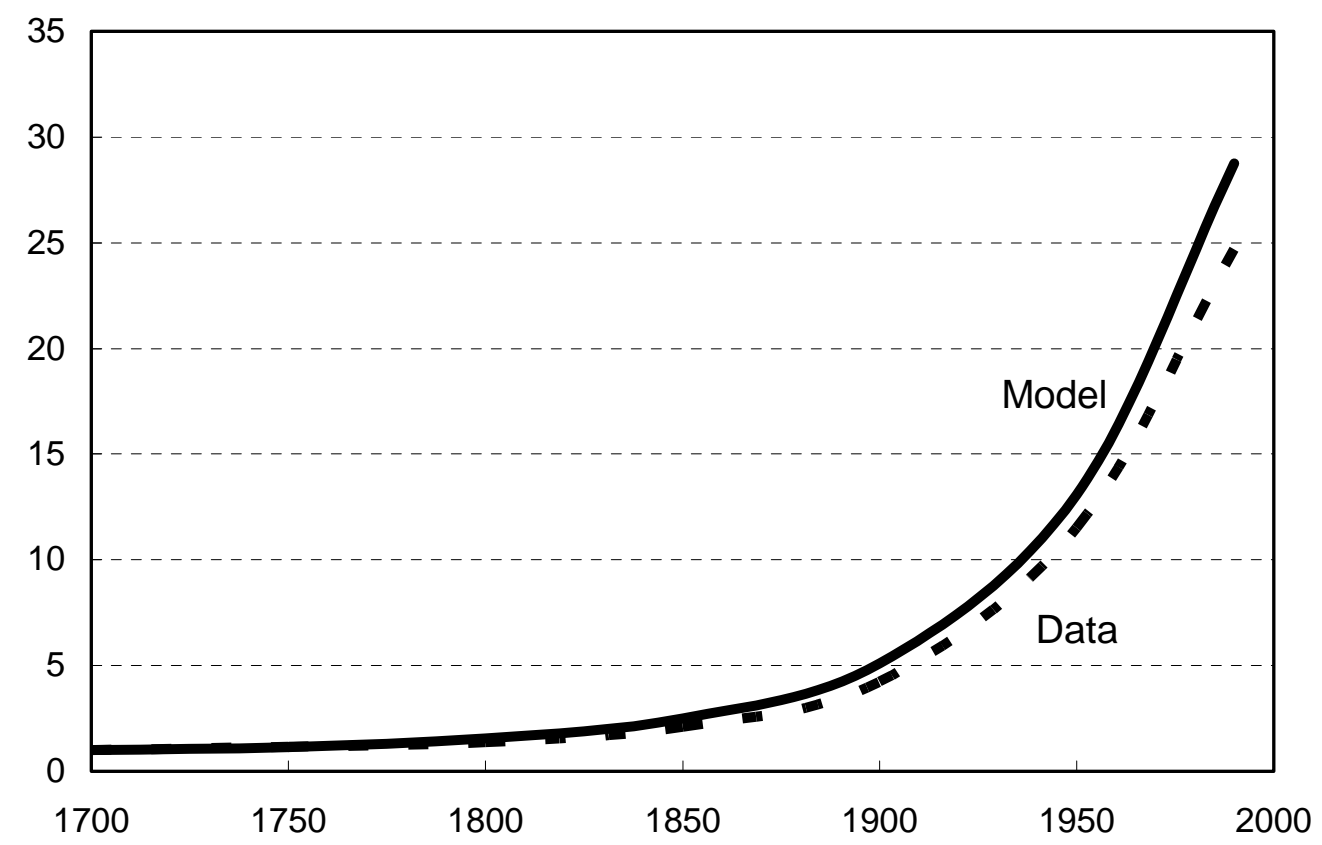

Source: Maddison (1995) 
Figure 5: Predicted Growth Rate of per Capita Output, 1700 - 2000

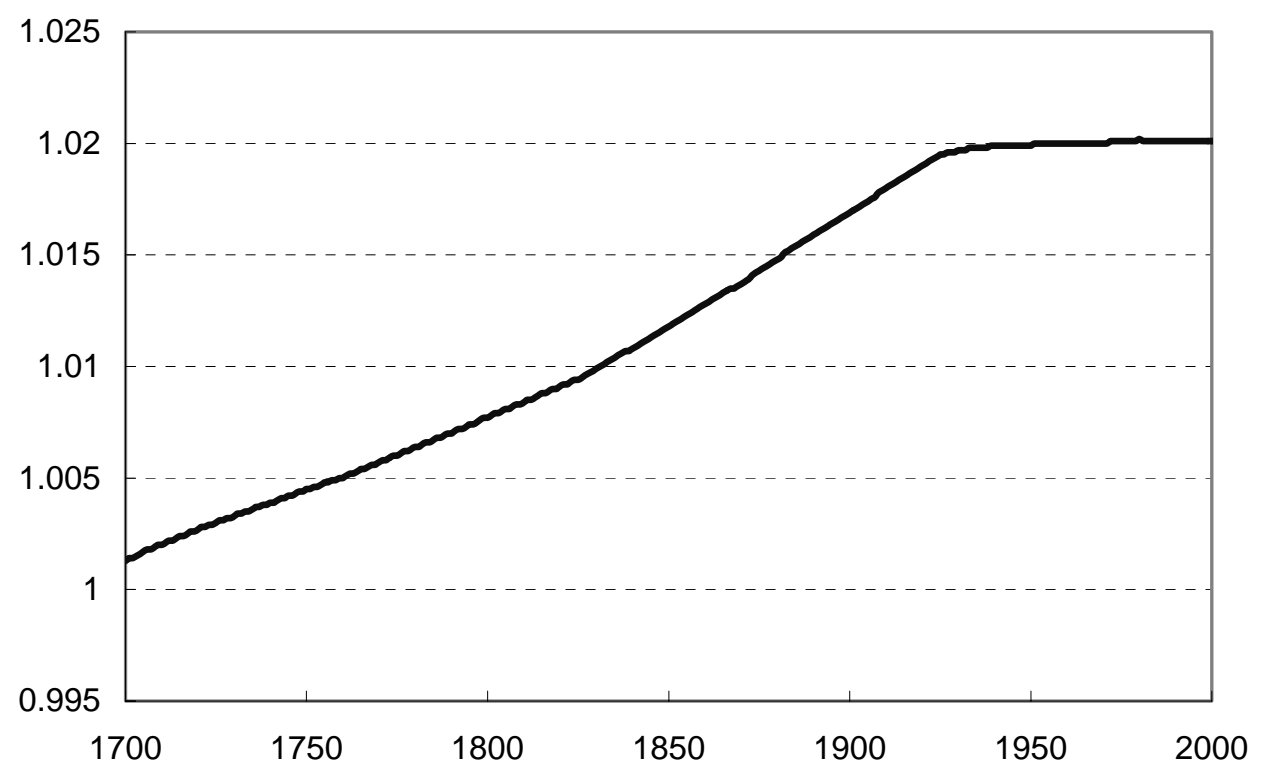

Figure 6: Predicted Factor Rental Prices $(1700=1), 1700$ - 2000

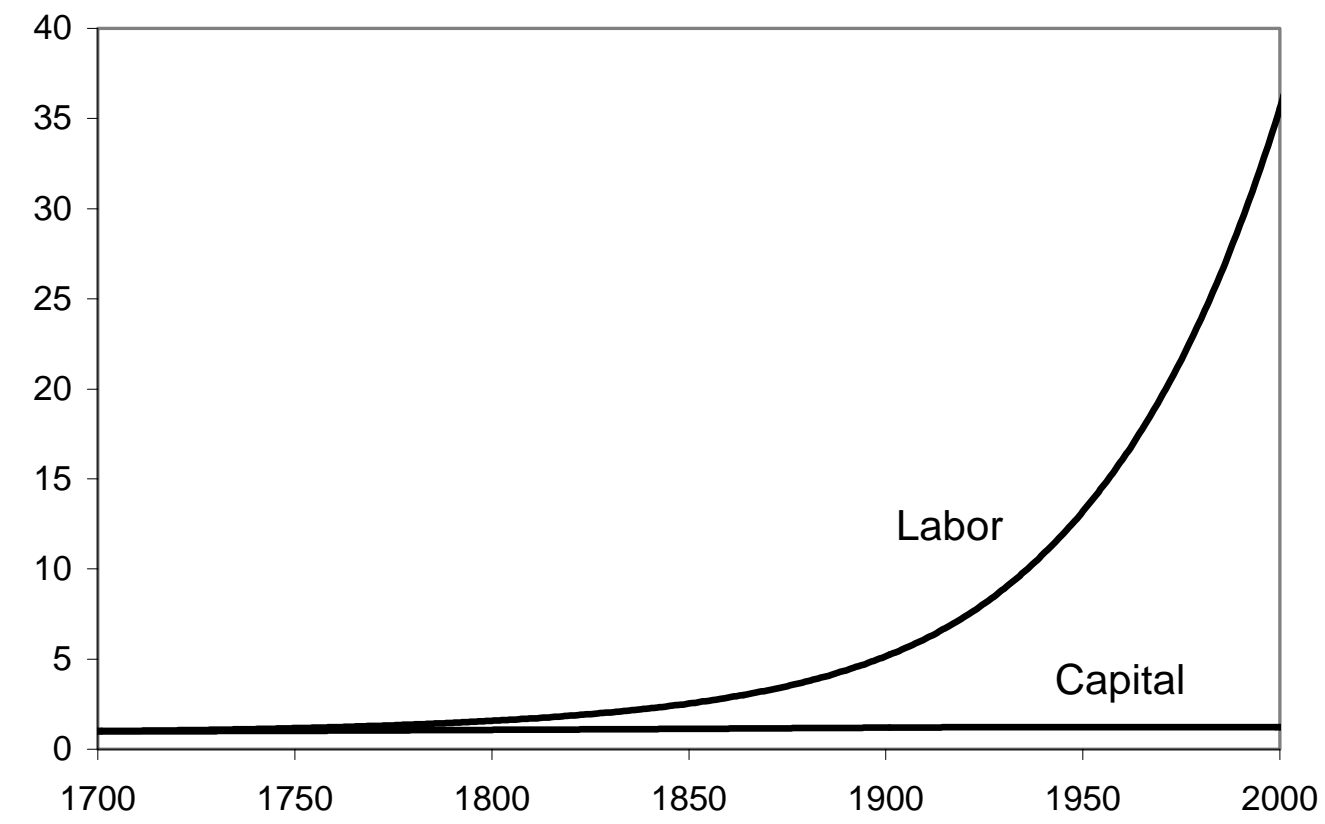


Figure 7: Different Countries Start at Different Dates, Income per Capita in 1990 \$U.S.

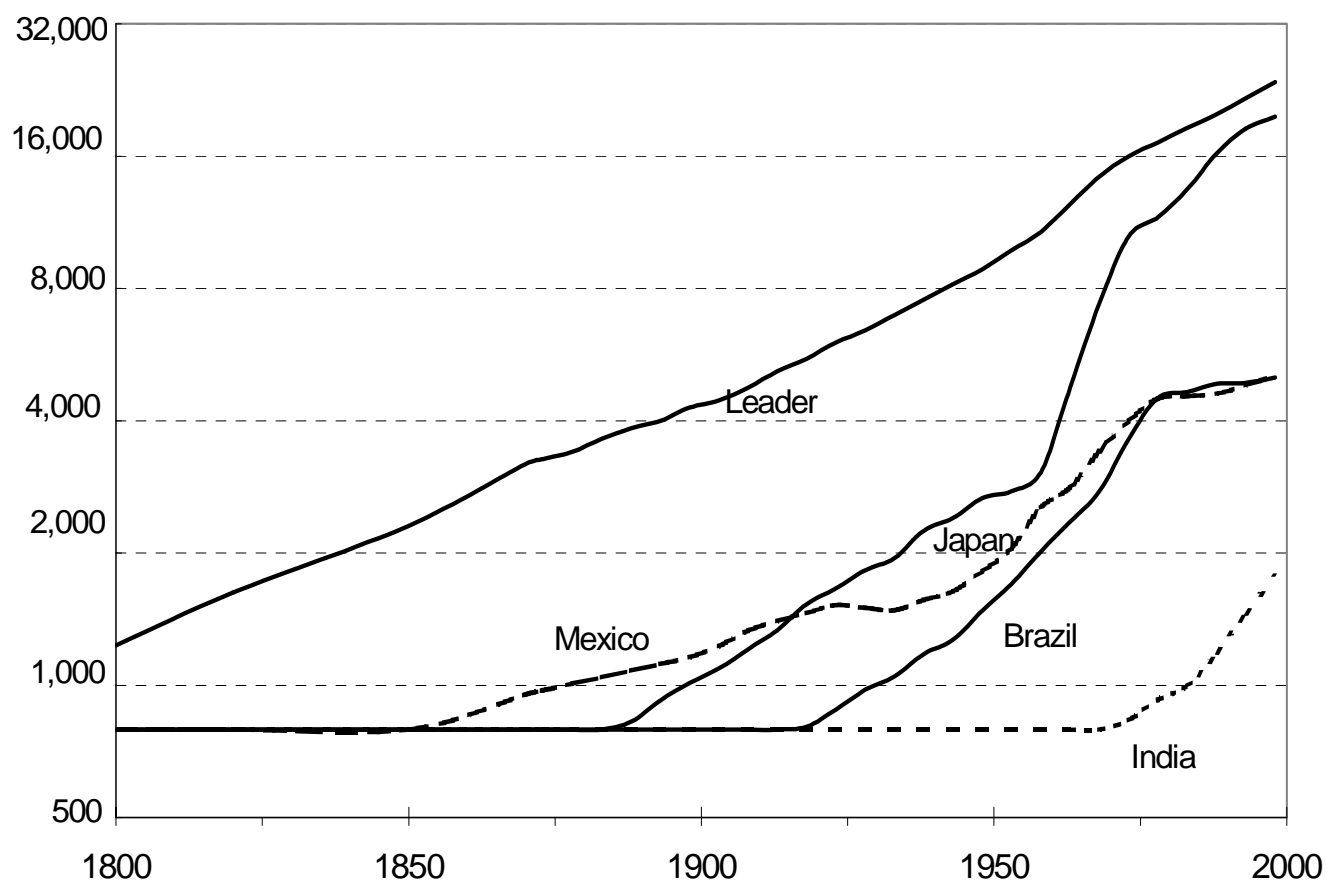

Source: Maddison (1995)

Figure 8: Predicted Income per Capita Relative to the Leader

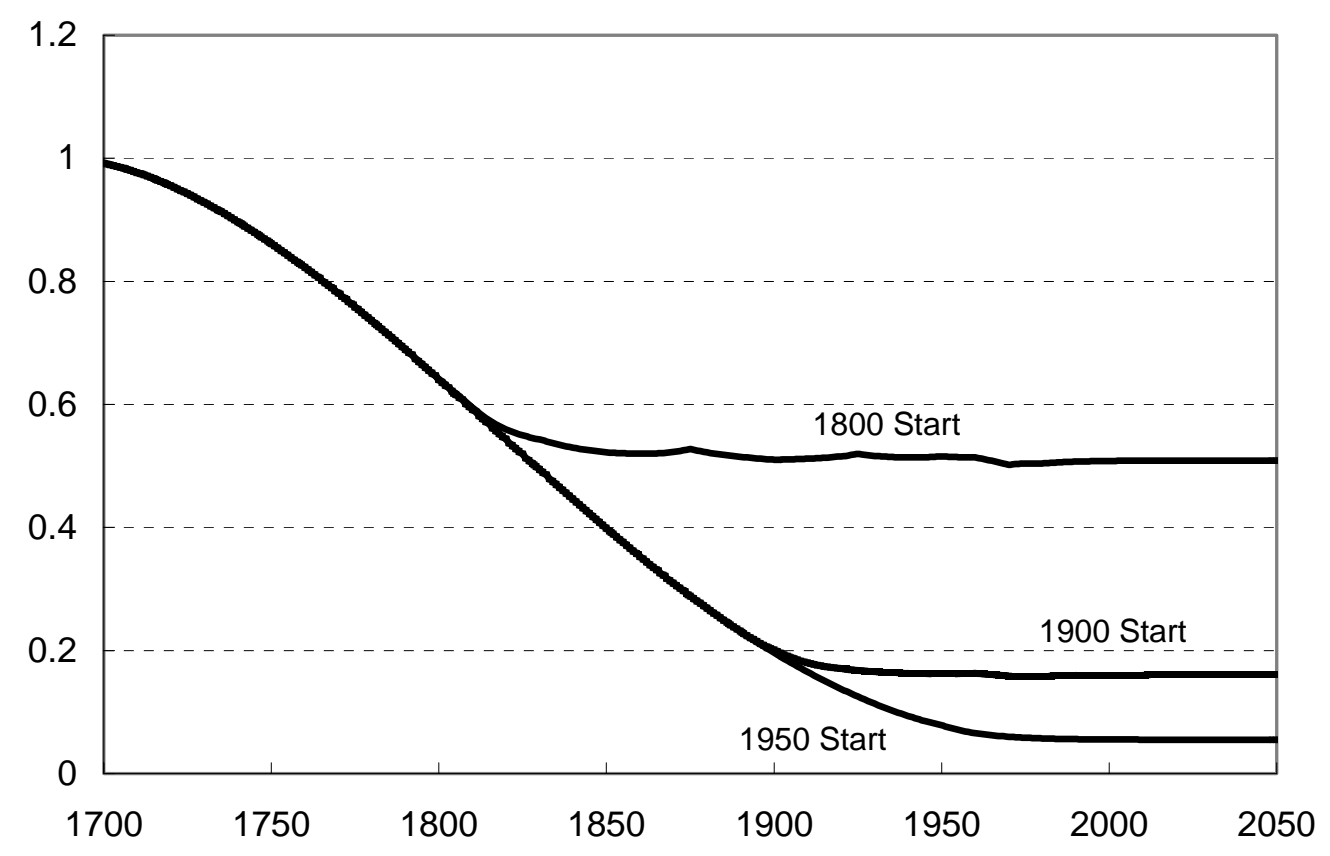


Figure 9: Years for Income per Capita to Grow from 2,000 to 4,000 (1990 \$U.S.)

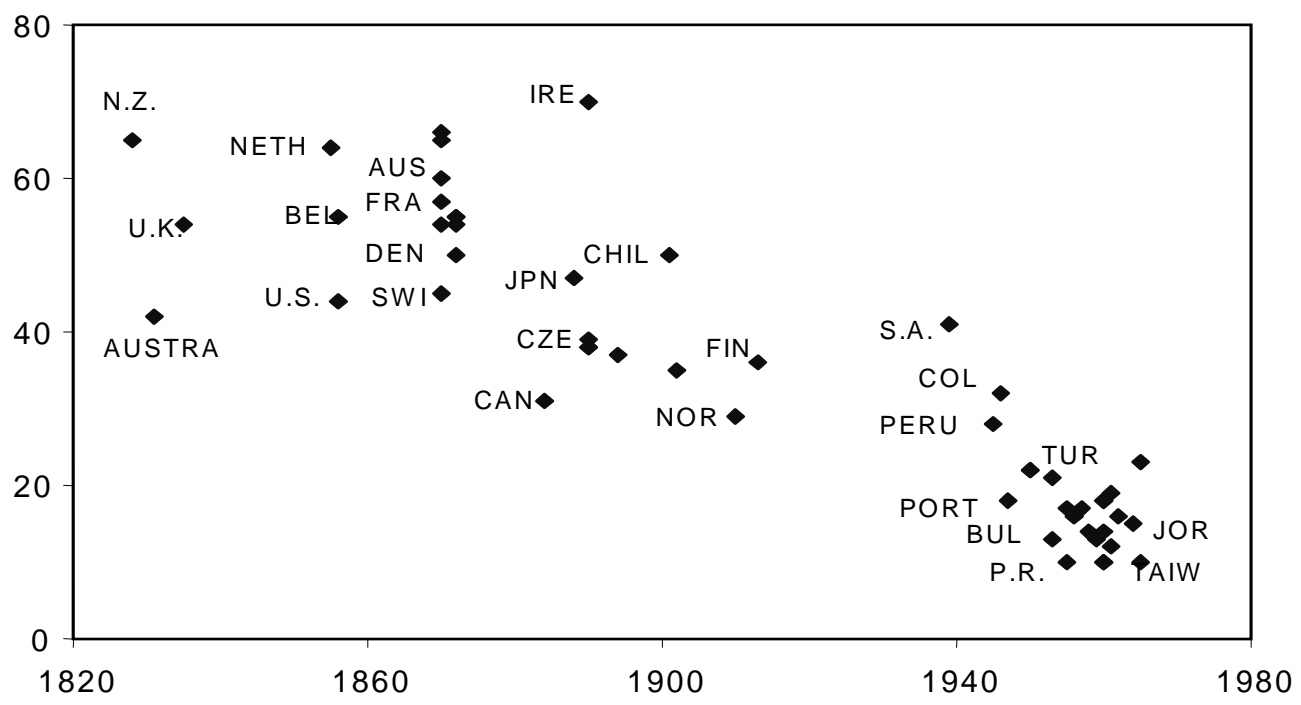

Source: Maddison (1995) and Summers and Heston (1991)

Figure 10: Income per Capita 1900-95 (1990 \$US)

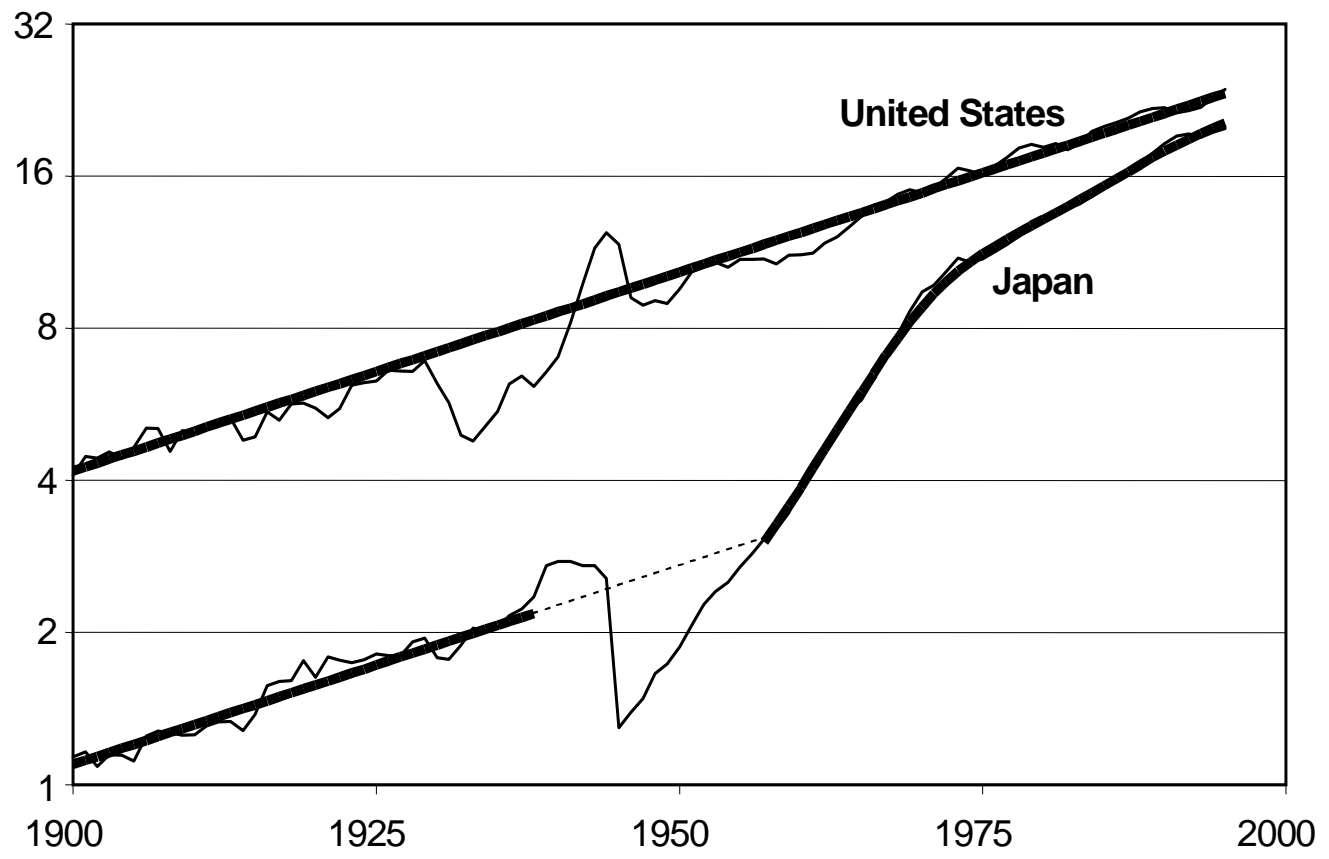

Source: Maddison (1995) and Summers and Heston (1991) 
Figure 11: Growth Miracles: Income per Capita as Fraction of the Leader

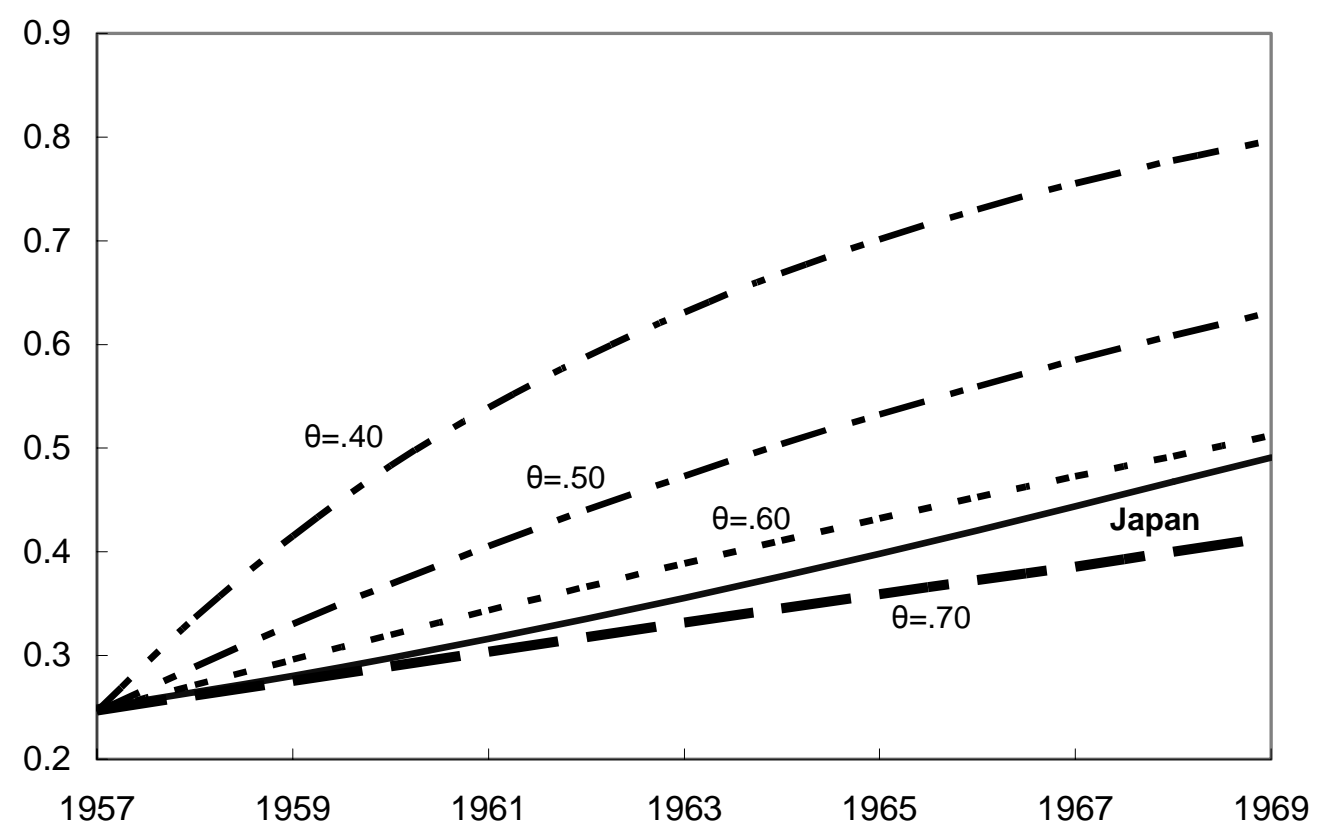

Source: Summers and Heston (1991) 